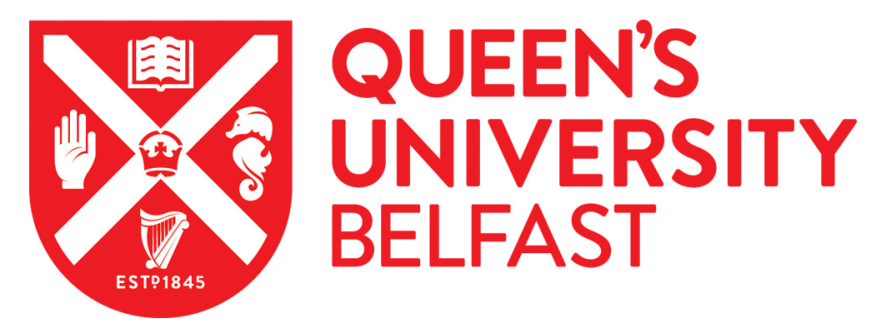

\title{
Breaking down the cell wall: strategies for antibiotic discovery targeting bacterial transpeptidases
}

Cochrane, S., \& Lohans, C. T. (Accepted/In press). Breaking down the cell wall: strategies for antibiotic discovery targeting bacterial transpeptidases. European journal of medicinal chemistry.

Published in:

European journal of medicinal chemistry

Document Version:

Peer reviewed version

Queen's University Belfast - Research Portal:

Link to publication record in Queen's University Belfast Research Portal

\section{Publisher rights}

Copyright 2020 Elsevier.

This manuscript is distributed under a Creative Commons Attribution-NonCommercial-NoDerivs License

(https://creativecommons.org/licenses/by-nc-nd/4.0/), which permits distribution and reproduction for non-commercial purposes, provided the author and source are cited.

\section{General rights}

Copyright for the publications made accessible via the Queen's University Belfast Research Portal is retained by the author(s) and / or other copyright owners and it is a condition of accessing these publications that users recognise and abide by the legal requirements associated with these rights.

Take down policy

The Research Portal is Queen's institutional repository that provides access to Queen's research output. Every effort has been made to ensure that content in the Research Portal does not infringe any person's rights, or applicable UK laws. If you discover content in the Research Portal that you believe breaches copyright or violates any law, please contact openaccess@qub.ac.uk. 


\section{Breaking down the cell wall: strategies for antibiotic discovery targeting bacterial transpeptidases}

Stephen A. Cochrane ${ }^{1}$ and Christopher T. Lohans ${ }^{2 *}$

${ }^{1}$ School of Chemistry and Chemical Engineering, David Keir Building, Stranmillis Road, Queen's University Belfast, Belfast, UK, BT9 5AG, s.cochrane@qub.ac.uk

${ }^{2}$ Department of Biomedical and Molecular Sciences, Queen's University, Kingston, Canada, K7L 3N6, christopher.lohans@queensu.ca

*Address correspondence to the corresponding author:

Dr. Christopher T. Lohans, Tel: 1 (613) 533-2989, Email: christopher.lohans@ @ueensu.ca 


\begin{abstract}
The enzymes involved in bacterial cell wall synthesis are established antibiotic targets, and continue to be a central focus for antibiotic development. Bacterial penicillin-binding proteins (and, in some bacteria, L,D-transpeptidases) form essential peptide cross-links in the cell wall. Although the $\beta$-lactam class of antibiotics target these enzymes, bacterial resistance threatens their clinical use, and there is an urgent unmet need for new antibiotics. However, the search for new antibiotics targeting the bacterial cell wall is hindered by a number of obstacles associated with screening the enzymes involved in peptidoglycan synthesis. This review describes recent approaches for measuring the activity and inhibition of penicillin-binding proteins and L,Dtranspeptidases, highlighting strategies that are poised to serve as valuable tools for highthroughput screening of transpeptidase inhibitors, supporting the development of new antibiotics.
\end{abstract}

Keywords: antibiotic, transpeptidase, penicillin-binding protein, L,D-transpeptidase, assay, highthroughput 


\section{Introduction}

The bacterial cell envelope plays a critical role in survival, protecting bacteria against their environment [1]. The envelope of Gram-negative bacteria consists of an inner cytoplasmic membrane, an outer membrane, and a cell wall situated between them in the periplasmic space. Gram-positive bacteria are surrounded by a cytoplasmic membrane and a thick cell wall, but lack an outer membrane. The cell wall plays an important structural role, and allows bacteria to resist osmotic pressure from the cytoplasm. Peptidoglycan, the principal component of the cell wall, is a mesh-like network of polysaccharides reinforced with peptide cross-links [2].

The final monomeric precursor of peptidoglycan, lipid II, is a lipid-linked disaccharide bearing a peptide sidechain [3]. Lipid II is assembled into peptidoglycan principally through the enzymatic activities of bacterial penicillin-binding proteins (PBPs) (Figure 1) [4]. The disaccharide unit of lipid II is first incorporated into the peptidoglycan polysaccharide backbone by class A PBPs, as well as other recently characterized peptidoglycan polymerases [4,5]. Then, the transpeptidase domains of class A and B PBPs catalyze transpeptidation reactions between the pentapeptide chains belonging to these newly incorporated subunits with other nearby peptide chains in peptidoglycan, forming $4 \rightarrow 3$ cross-links (i.e., the fourth residue of one peptide chain is covalently linked to the third residue of another chain). The class C PBPs, which are smaller than classes A and B, perform other functions in peptidoglycan regulation and degradation, typically acting as carboxypeptidases (hydrolytically removing the terminal residue of the peptide chain) or endopeptidases (cleaving the cross-link formed by the transpeptidase activity) (Figure 1).

The peptidoglycan of some bacteria, notably Mycobacterium spp., contains high levels of $3 \rightarrow 3$ cross-links (i.e., the third residue of one peptide chain is covalently linked to the third residue of another chain) (Figure 1) [6]. These non-classical cross-links are formed by L,D-transpeptidases 
(Ldts), enzymes that are structurally unrelated to the transpeptidase domain occurring in PBPs [7,8]. While PBPs accept pentapeptide substrates, Ldt activity first requires a carboxypeptidase to cleave the fifth residue from the pentapeptide chain (Figure 1) [9]. Similar to the sortase family of transpeptidases, some Ldts catalyze other transpeptidation reactions, covalently anchoring a protein substrate (i.e., Braun's lipoprotein) to the peptide chains in peptidoglycan [10,11].

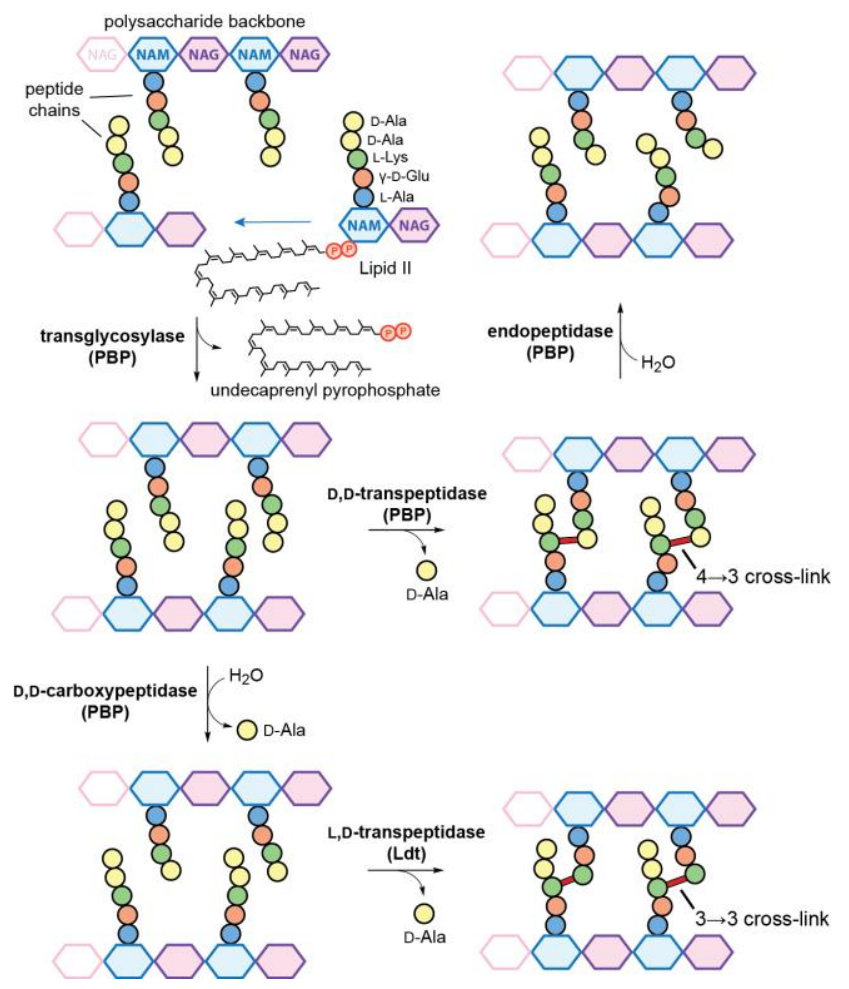

Figure 1. Overview of the roles of penicillin-binding proteins and L,D-transpeptidases in bacterial peptidoglycan synthesis and degradation. Penicillin-binding proteins (PBPs) with transglycosylase activity incorporate the disaccharide core of lipid II into a growing glycan strand. Then, the transpeptidase domain of a PBP may form $4 \rightarrow 3$ cross-links between peptide strands (D,D-transpeptidase activity), cleave these cross-links (endopeptidase activity), or cleave the terminal D-Ala residue from the peptide (D,D-carboxypeptidase activity). The product of the 
carboxypeptidase may then by accepted by L,D-transpeptidases (Ldts), forming $3 \rightarrow 3$ peptide crosslinks. The peptidoglycan shown here represents a form occurring primarily in Gram-positive bacteria, in which the pentapeptide chain bears a L-Lys residue in the third position. NAM and NAG refer to $N$-acetylmuramic acid (MurNAc) and $N$-acetylglucosamine (GlcNAc), respectively. Note that enzymes other than PBPs may also catalyze the reactions depicted (e.g., monofunctional glycosyltransferases, metallo-D,D-carboxypeptidases) [9,12].

The enzymes involved in peptidoglycan synthesis, particularly the PBPs, are clinically validated antibiotic targets [4,13]. Their value as targets derives from the critical role of peptidoglycan in bacterial survival, the complex biosynthetic pathway required for peptidoglycan synthesis, and the absence of homologous pathways in eukaryotes, decreasing the likelihood of off-target effects. The most important class of antibiotics targeting peptidoglycan synthesis are the $\beta$-lactams (e.g., penicillins, cephalosporins, carbapenems), which target the transpeptidase domains of PBPs, and in some cases, Ldts $[14,15]$. $\beta$-Lactams act as covalent inhibitors, blocking the formation of peptide cross-links in peptidoglycan.

The clinical use of $\beta$-lactam antibiotics, and indeed of all antibiotics, is critically threatened by the emergence of resistant bacteria. Resistance to $\beta$-lactams occurs through a number of different mechanisms, particularly through the production of $\beta$-lactamase enzymes in Gramnegative bacteria $[16,17]$. All current $\beta$-lactams are susceptible to degradation by $\beta$-lactamases, with different enzymes demonstrating varying levels of activity against different $\beta$-lactams [18]. Thus, there is an urgent and unmet need for the discovery of new antibiotics. Although bacterial transpeptidases are established antibiotics targets, inhibitor screening for these enzymes is often challenging, due in large part to the structural complexity of their substrates. 
In this review, we begin by describing synthetic and enzymatic approaches for preparing lipid II, the monomeric PBP substrate. We then highlight promising recent approaches for assaying the transpeptidase activities of PBP and Ldts, based principally on interactions with substrate analogues and $\beta$-lactam-based probes. This review does not cover PBP transglycosylase activity or the sortase family of transpeptidases, which were covered in excellent recent reviews [19-21]. There have also been excellent reviews by Wollmer, Walker, and Kahne describing how PBP transpeptidase activity assays have contributed to a better understanding of the in vivo functions of PBPs [22,23]. Our aim here is to describe how the mechanisms by which PBPs and Ldts interact with their substrates and inhibitors may be exploited for the development of in vitro transpeptidases assays, including some which are amenable to high-throughput inhibitor discovery.

\section{Preparation of Lipid II and Analogues}

Lipid II is the final monomeric intermediate in the peptidoglycan biosynthetic pathway (Figure 2A) [24]. It is synthesized in the cytoplasm, flipped to the external face of the cytoplasmic membrane, and then incorporated into peptidoglycan (Figure 2B). Although the structure of lipid II varies across different bacterial species [25], all variants are composed of three main structural elements: a $\beta-1,4$ linked $N$-acetylmuramic acid (MurNAc, or NAM)- $N$-acetylglucosamine (GlcNAc, or NAG) disaccharide core, a peptide chain ligated to the MurNAc carboxylic acid moiety, and a $\left(Z_{8}, E_{2}, \omega\right)$-undecaprenyl lipid tail attached to the MurNAc anomeric position through a diphosphate (Figure 2A). Synthetic preparation of lipid II is challenging due to its structural complexity, while isolation of natural lipid II is limited due to the low levels at which it occurs in bacteria under normal conditions. Nonetheless, methods have been developed to prepare 
lipid II and analogues through total chemical synthesis, chemoenzymatic synthesis, or isolation. Access to lipid II analogues has opened up new strategies for investigating the activity and mechanism of PBPs, as well as the other enzymes involved in peptidoglycan biosynthesis.

A
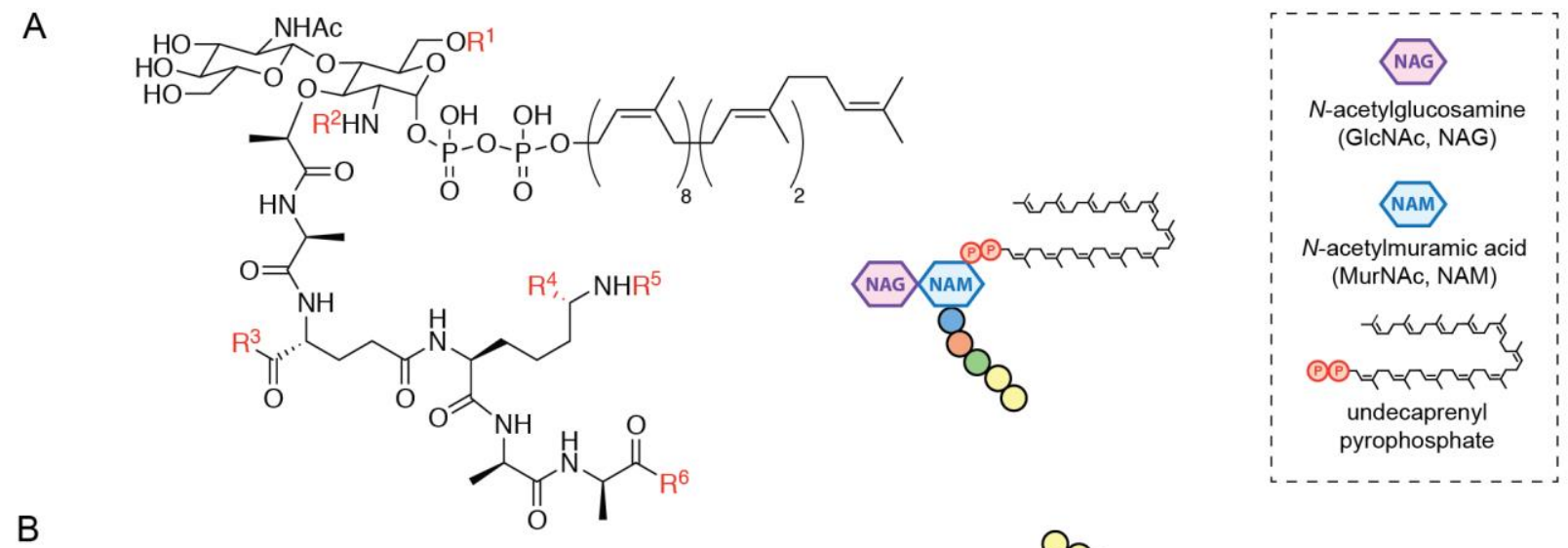

B
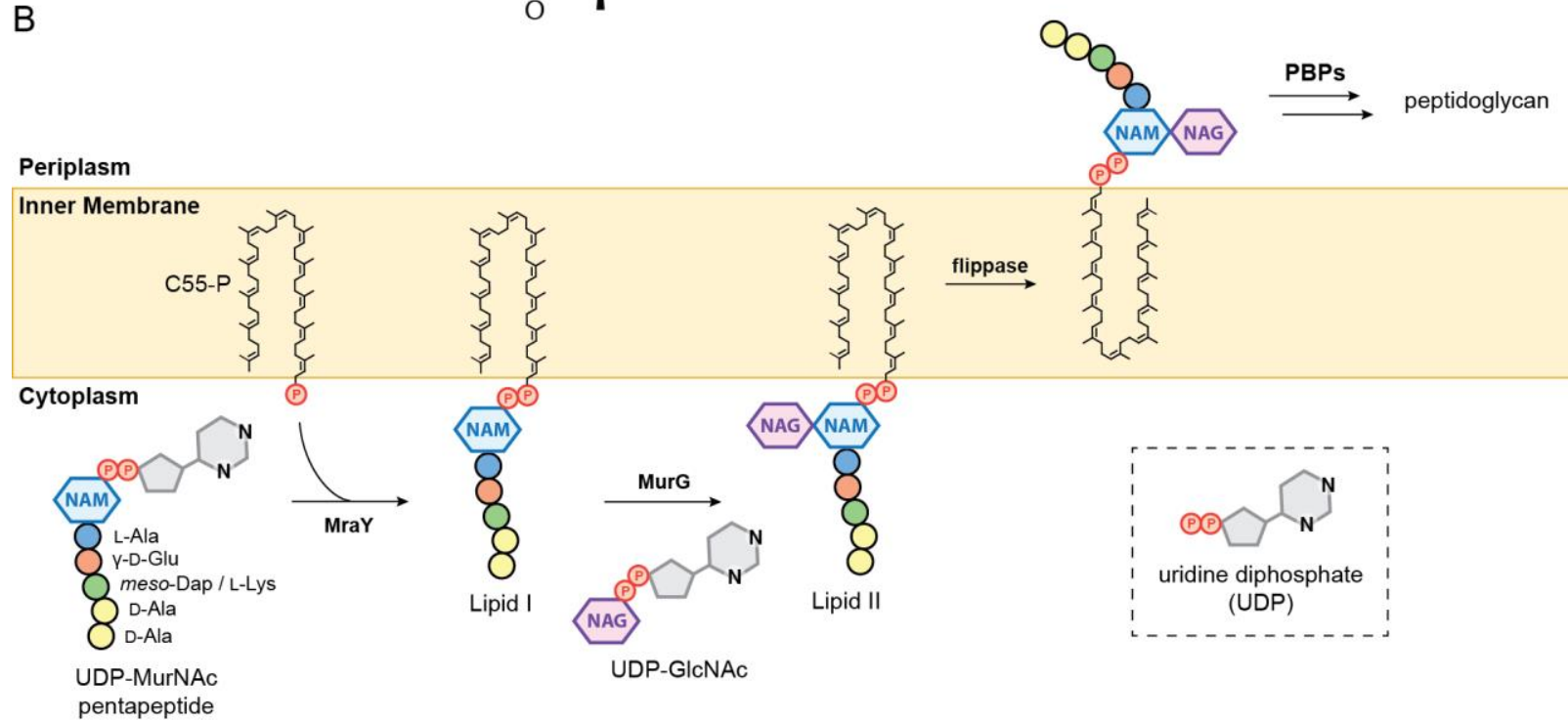

Figure 2. Lipid II structure and biosynthesis. (A) Chemical structure of lipid II. The variable positions are shown in red. $\mathrm{R}^{1}=\mathrm{H}, \mathrm{Ac} ; \mathrm{R}^{2}=\mathrm{H}, \mathrm{Ac} ; \mathrm{R}^{3}=\mathrm{OH}, \mathrm{OMe}, \mathrm{NH}_{2} ; \mathrm{R}^{4}=\mathrm{H}, \mathrm{CO}_{2} \mathrm{H} ; \mathrm{R}^{5}=$ Gly5, Ala2, Ala-Ser/Ala, D-Asp; $\mathrm{R}^{6}=\mathrm{OH}, \mathrm{OMe}, \mathrm{NH}_{2}$. These structural variations are described in detail by Münch et al. [25]. The components of the cartoon representations of lipid II and peptidoglycan used throughout this review are defined in the dashed box. (B) Scheme showing the 
biosynthetic assembly of lipid II, and its incorporation into peptidoglycan in a model Gramnegative bacterium. In Gram-negative bacteria, the third amino acid of the pentapeptide chain is typically meso-diaminopimelic acid (meso-Dap), while it is typically L-Lys in Gram-positive bacteria. MraY catalyzes the transfer of UDP-MurNAc pentapeptide to a C55 undecaprenyl phosphate chain, forming lipid I. Then, MurG transfers GlcNAc to lipid I, yielding lipid II. Flippase enzymes translocate lipid II to the outer face of the inner membrane, where it can be incorporated into peptidoglycan by PBPs.

The first total syntheses of lipid II were reported by groups at DuPont Pharmaceuticals [26] and Eli Lilly [27], with subsequent groups employing variations of this strategy to prepare analogues [28-33]. Most total syntheses employ a modular strategy, wherein a MurNAc acceptor, GlcNAc donor, peptide chain, and polyprenol phosphate are prepared individually, then combined into lipid II at a late stage (Scheme 1A). Here lies the major advantage of total chemical synthesis over other methods. Theoretically any modification can be performed on any one of these fragments, allowing the preparation of many different lipid II analogues. However, this synthesis is challenging, and is technically beyond the capabilities of most end-users of lipid II derivatives. Furthermore, the synthesis is lengthy, typically requiring $>20$ steps, and is low yielding.

In the chemoenzymatic preparation of lipid II analogues, chemical synthesis is used to prepare or modify (i.e., label) lipid II intermediates, which are then converted enzymatically to lipid II (Scheme 1B). An excellent review describing biochemical approaches for lipid II production was prepared by Breukink and Vollmer, and we refer readers to this for a detailed overview of past chemoenzymatic approaches [22]. Akin to total synthesis, this method is also modular, making use of the phosphotransferase MraY and/or the glycosyltransferase MurG 
(Figure 2B). However, the enzymatic steps impose limitations related to substrate specificity. MraY utilizes two substrates, Park's nucleotide and a polyprenol phosphate, and tolerates a broad range of modifications. MraY is capable of utilizing polyprenyl phosphates of varying chain lengths, but does not accept alkyl phosphates lacking the alkene moieties found in polyprenols [34,35]. Recent work by Kurosu and coworkers has shown that synthetic derivatives of Park's nucleotide containing dansyl or fluorescein labels on L-Lys3 are processed by MraY into lipid I (the monosaccharide precursor to lipid II) [35]. However, the first two amino acids of the pentapeptide chain and the C-4 configuration of MurNAc are essential for MraY recognition in Bacillus subtilis [36]. One method to overcome the substrate limitations of MraY is to chemically synthesize the desired lipid I fragment, and then use MurG to add GlcNAc [37]. However, Kurosu and coworkers have also shown that MurG may not tolerate lipid I analogues labelled at L-Lys3 [35].

The final method to access lipid II analogues involves direct isolation from bacteria. An elegant method to isolate lipid II from Escherichia coli, Staphylococcus aureus and B. subtilis was recently reported by Walker and Kahne, providing pure lipid II far more quickly and conveniently than synthetic and enzymatic methods [38]. Growth of B. subtilis with low levels of vancomycin inhibits peptidoglycan synthesis, resulting in lipid II accumulation, and allowing for sub-milligram quantities of lipid II to be isolated. The transglycosylase inhibitor moenomycin was used as part of an analogous approach to extract lipid II from S. aureus. However, in E. coli, the outer membrane interferes with the activities of both vancomycin and moenomycin. Instead, a strain containing a functional mutant of the lipid II flippase MurJ (MurJ ${ }^{\mathrm{A} 29 \mathrm{C}}$ ) could be treated with a cysteine capping agent, leading to lipid II accumulation. The material prepared by these isolation methods can be modified through several late-stage functionalization approaches, e.g. the direct 
modification of the L-Lys3 side chain. Grimes et al. recently reported a strategy to incorporate a bioorthogonal azide or alkyne tag by feeding E. coli labelled MurNAc derivatives, which are then incorporated into lipid II through peptidoglycan-recycling enzymes [39]. A combination of the approaches reported by Walker, Kahne, and Grimes could be an excellent way to rapidly generate novel labelled lipid II analogues.

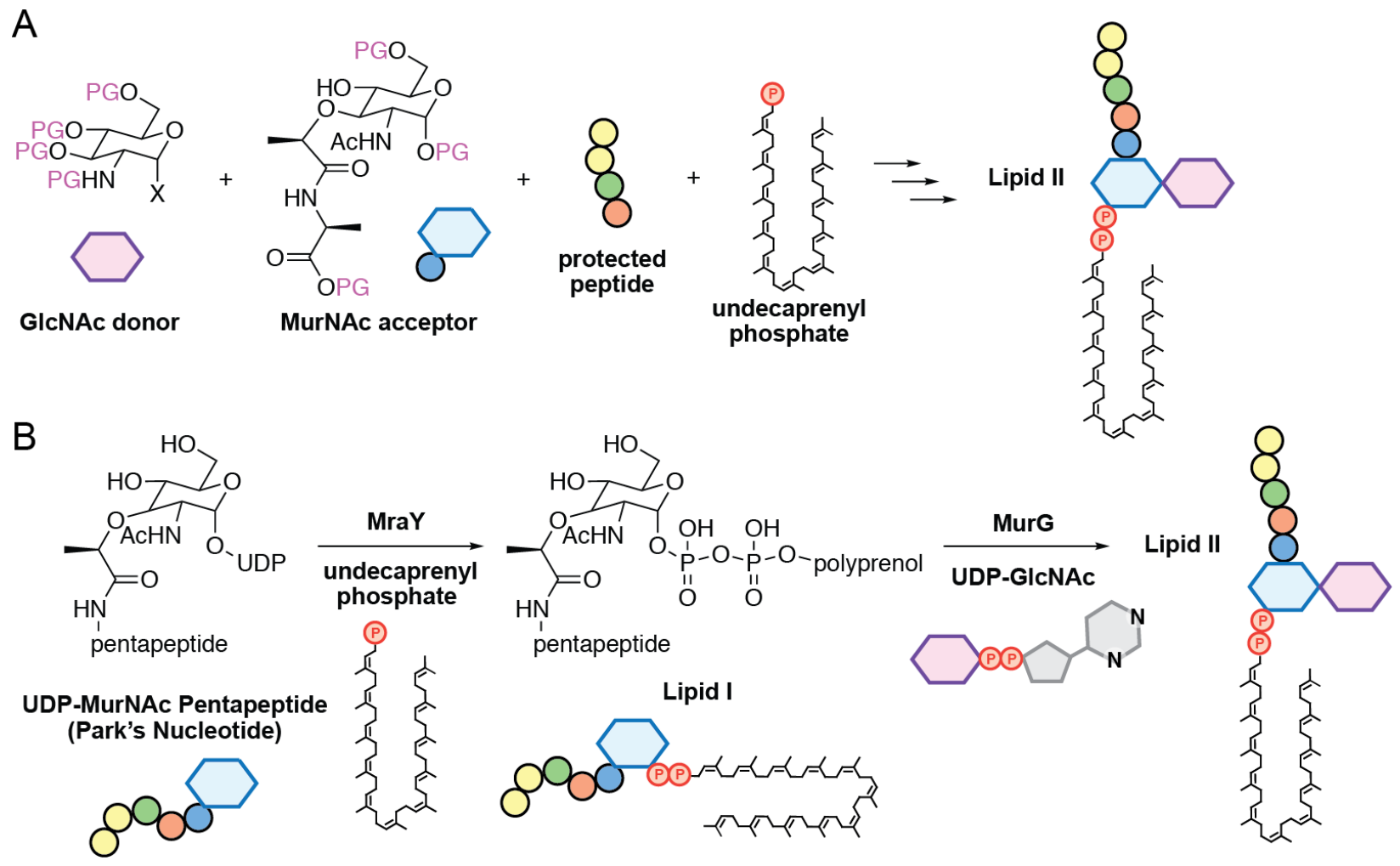

Scheme 1. Synthetic methods to prepare lipid II and analogues. (A) Total chemical synthesis of lipid II follows a modular strategy, initially preparing protected saccharide and peptide moieties, followed by their late stage assembly into lipid II. (B) Chemoenzymatic synthesis of lipid II may also follow a modular strategy, employing phosphotransferase MraY and glycosyltransferase MurG with isolated or chemically synthesized substrates. These enzymes tolerate a range of 
substrate substitutions, allowing for the preparation of lipid II analogues. PG is protecting group, and UDP is uridine diphosphate.

Labelled lipid II derivatives have been extensively used to assay glycosyltransferase activity and identify inhibitors of several different peptidoglycan synthases, and we refer readers to a recent review by Wong and Ma for more information on this topic [19]. Lipid II has been applied less frequently to the study of the transpeptidase activities of PBPs and Ldts, although there have been promising reports; for example, a high-throughput transpeptidase assay was devised based on the preparation and modification of isotopically labelled lipid II in a bacterial membrane extract [40]. Based on recent advances in the preparation of lipid II, and with consideration of the transpeptidase assays described in subsequent sections of this review, it is clear that labelled lipid II derivatives could be a valuable tool for discovering inhibitors targeting bacterial transpeptidases.

\section{Penicillin-Binding Proteins}

\section{Introduction}

Bacteria employ several PBP enzymes for the synthesis and degradation of peptidoglycan, with different bacterial species producing varying numbers of PBPs [4]. There is further diversity in terms of the sizes and functional domains of these PBPs. The high-molecular weight (HMW) PBPs are divided into classes A and B; class A enzymes have both glycosyltransferase and transpeptidase domains, while class B enzymes only have transpeptidase activity. These HMW PBPs play a principal role in peptidoglycan synthesis for most bacteria [22]. While the low- 
molecular weight (LMW) PBPs (or class C enzymes) also have a transpeptidase domain, this domain behaves primarily as a carboxypeptidase or endopeptidase in these enzymes [22].

Crystallographic studies have revealed the structure and likely mechanisms of the PBP transpeptidases [4]. Initial studies on LMW PBPs, such as the D,D-peptidase from Streptomyces R61, have provided much of our initial understanding of the interactions of PBPs with their substrates [41]. Overall, the structures of a broad range of HMW and LMW PBPs have now been solved [42-45]. The structure of the transpeptidase (or penicillin-binding) domain tends to be highly conserved, composed of an $\alpha$-helical subdomain interacting with another subdomain consisting of a $\beta$-sheet covered by three $\alpha$-helices (Figure 3A) [4]. The active site is made up of residues from both subdomains, centered around a nucleophilic serine residue (e.g., Ser510 of PBP1b; Figure 3A). Key conserved motifs contribute residues to this active site, including the nucleophilic serine (part of the conserved SXXK motif), an active site loop between two $\alpha$-helices (bearing the SXN motif), and a neighbouring $\beta$-strand [bearing the KTG(T/S) motif] [4]. 
A

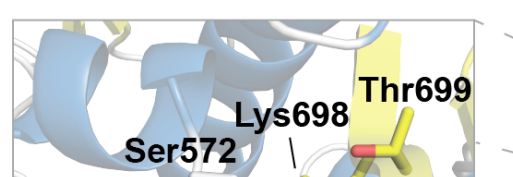

Lys513

Asn574

B

Transpeptidase activity

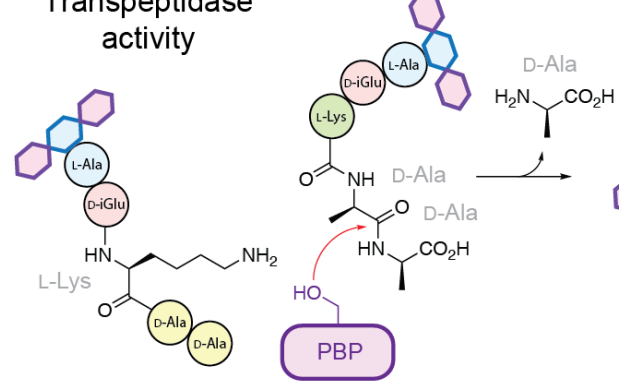

C

Carboxypeptidase activity

Ser510 Thr701

${ }^{-}-$
UB2H domain

transglycosylase domain

transpeptidase

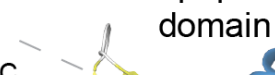

moenomycin

N
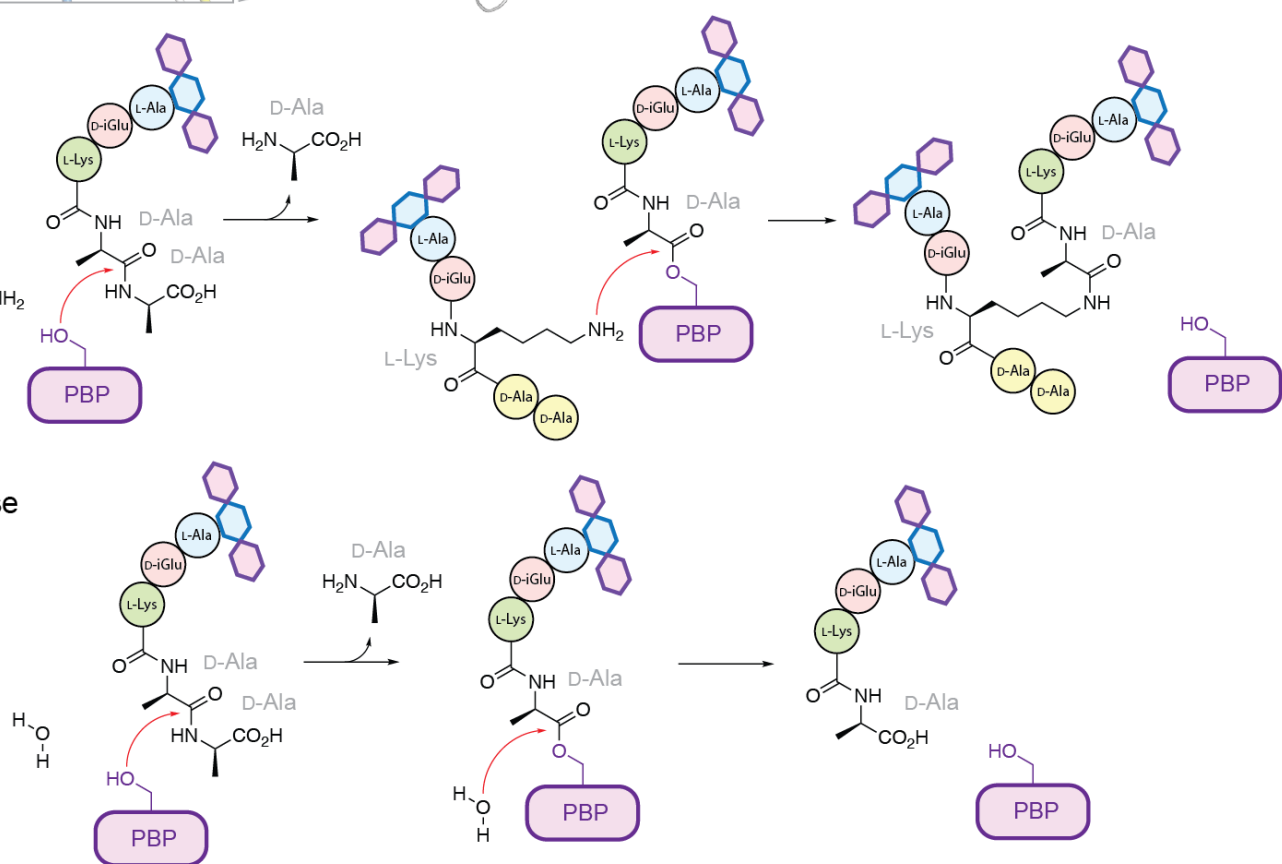

D
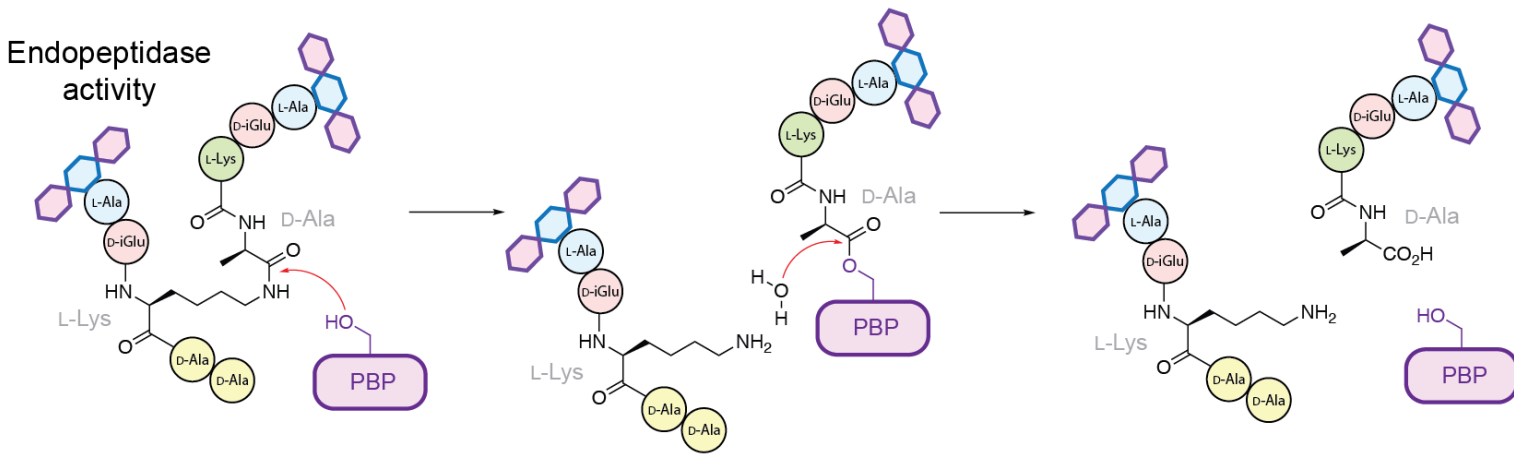

E
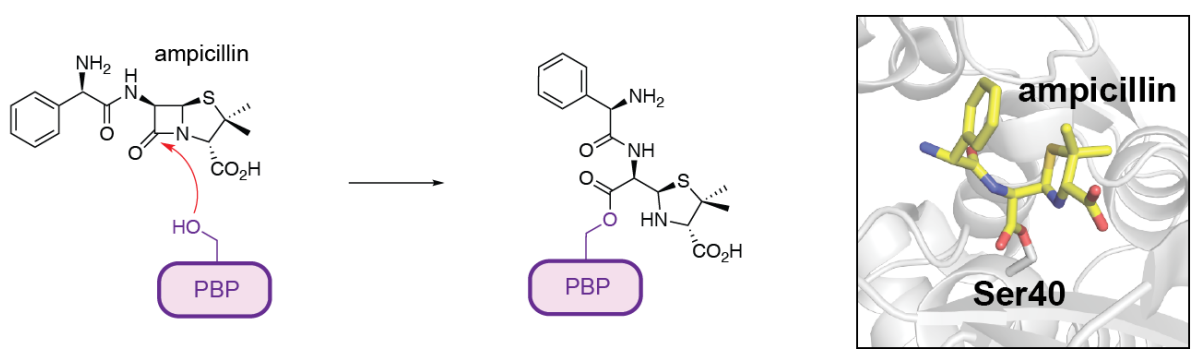

13 
Figure 3. Overview of PBP transpeptidase structure, mechanism, and inhibition by $\beta$-lactam antibiotics. (A) View of the crystal structure of PBP1b from E. coli (PDB 3VMA) [43], with $\alpha$ helices shown in blue and $\beta$-strands in yellow. The distinct transglycosylase, UB2H, and transpeptidase domains are indicated. The transglycosylase inhibitor moenomycin is shown in a stick representation. The protein termini are indicated with $\mathrm{N}$ and $\mathrm{C}$. The inset shows a view of the enzyme active site, including the nucleophilic serine Ser510 and the conserved catalytic motifs described in the text. Schemes showing the mechanisms of PBP (B) transpeptidase activity, (C) carboxypeptidase activity, and (D) endopeptidase activity. Note that the length of the glycan backbone, as represented by hexagons, is variable and is not shown fully in this figure. The structure of peptidoglycan shown in the figure represents a form commonly seen in Gram-positive bacteria, with L-Lys in the third position of the peptide chain. (E) Scheme showing the acylation of the PBP transpeptidase serine nucleophile by the $\beta$-lactam antibiotic ampicillin. The resulting acyl-enzyme complex, as shown crystallographically for the complex derived from ampicillin and PBP6 (PDB 3ITA) [44], is typically resistant to hydrolysis, inhibiting enzymatic activity.

Following substrate binding, the catalytic mechanism of the PBP transpeptidase domain begins with the attack of the nucleophilic serine onto the amide linkage between D-Ala4 and DAla5 of the substrate pentapeptide (i.e., the donor peptide) (Figure 3B). This leads to the cleavage of the amide bond, releasing D-Ala and forming a covalent ester-based intermediate involving the PBP serine side chain and the tetrapeptide chain. For PBPs with transpeptidase activity, an amino group on the side chain of residue 3 (e.g., L-Lys) of another peptide chain (i.e., the acceptor peptide) nucleophilically attacks the ester linkage, forming a new amide bond and releasing the enzyme serine residue. For some PBPs, free D-amino acids may act in place of the acceptor peptide, 
attacking the covalent peptide-enzyme complex and yielding a pentapeptide chain with an alternative terminal residue [46]. The PBP carboxypeptidases use a nucleophilic water molecule in place of the acceptor peptide, hydrolytically cleaving the terminal D-Ala and producing a tetrapeptide chain without a peptide cross-link (Figure 3C). The LMW PBPs with endopeptidase activity catalyze what is effectively the reverse reaction of the transpeptidases, with the nucleophilic serine attacking the peptide cross-link, forming an ester-based covalent peptideenzyme complex and releasing the original acceptor peptide (Figure 3D); then, attack by a water molecule releases the resulting tetrapeptide, thereby hydrolyzing the cross-link.

$\beta$-Lactam antibiotics are the most clinically important inhibitors of PBP transpeptidase activity. The nucleophilic serine of the transpeptidase domain attacks the strained $\beta$-lactam ring present in all antibiotics of this class, resulting in a covalent adduct in which the serine is acylated by the antibiotic (Figure 3E). These covalent complexes are typically stable, blocking the enzyme from catalyzing the formation of cross-links in peptidoglycan. Glycopeptide antibiotics such as vancomycin are another major class of inhibitors which interfere with PBP transpeptidase activity, through a non-covalent binding interaction with the substrate pentapeptide chain.

\section{Assays}

In this section, we principally consider assays centered on the activity of the PBP transpeptidase domain (which may catalyze transpeptidase, carboxypeptidase, or endopeptidase reactions), focusing on approaches that are suitable for high-throughput inhibitor screening. As indicated above, recent reviews have described efforts towards identifying inhibitors of the PBP glycosyltransferase domain,[19] as well as functional investigations of PBP transpeptidase activity in bacteria $[22,23]$. 
Screening of PBP transpeptidases requires a number of important considerations. Many PBPs are membrane-associated proteins, complicating efforts to produce and purify these enzymes. PBPs vary in terms of their catalytic activity and their inhibitor susceptibility, and hence screening for one enzyme may not yield hits that target other PBPs. Furthermore, not all PBPs are essential to bacterial survival, and so inhibition of only one PBP may not lead to antibiotic activity. The natural substrates of PBPs are structurally complex, and efficient transpeptidase activity often requires pre-existing glycan polymers formed by PBPs (or other enzymes) with glycosyltransferase activity [47]. However, in spite of these complications, several strategies have been devised to study PBP transpeptidase activity, exploiting the mechanisms by which PBPs interact with their substrates and inhibitors. The methods described below, which are intended to highlight the diversity of approaches available as opposed to listing them comprehensively, are organized according to the enzymatic activity that they measure.

\section{Transpeptidase Activity}

Degradation strategies have been devised to examine the extent of peptide cross-links present in peptidoglycan, providing both in vivo and in vitro indications of transpeptidase activity. Typically, a muramidase enzyme (e.g., cellosyl, mutanolysin) is added to cleave the glycosidic linkages between GlcNAc and MurNAc sugars (Figure 4A) [48]. Then, treatment with sodium borohydride reduces the MurNAc sugar, and the products are analyzed by liquid chromatography (LC) methods. Biboy et al. applied such an approach to develop an assay for measuring the in vitro transpeptidase activity of PBP1B from E. coli with $\left[{ }^{14} \mathrm{C}\right]$-labeled lipid II [49]. Assay products were treated with cellosyl, sodium borohydride, and the resulting muropeptides were quantified by high pressure liquid chromatography (HPLC) with detection by scintillation counting. 
A
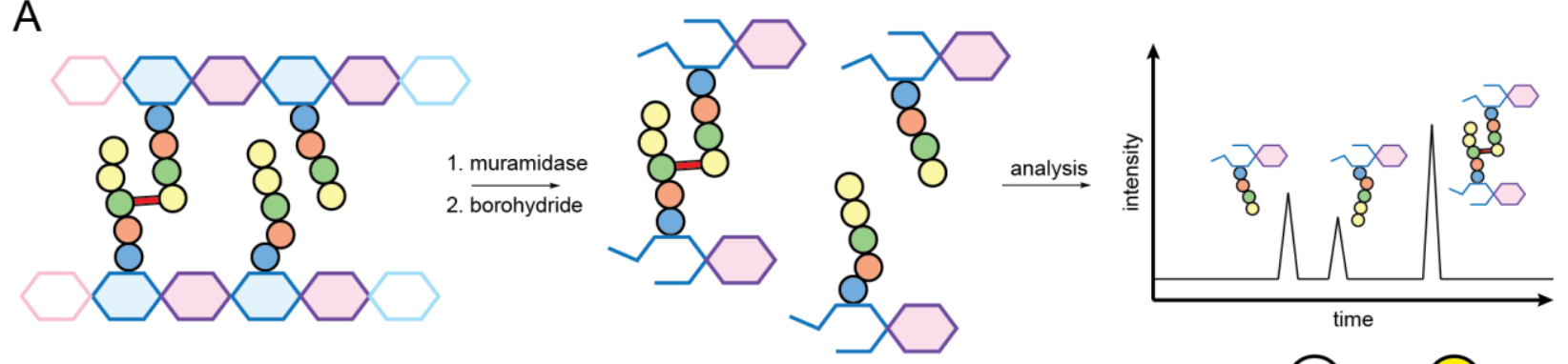

B
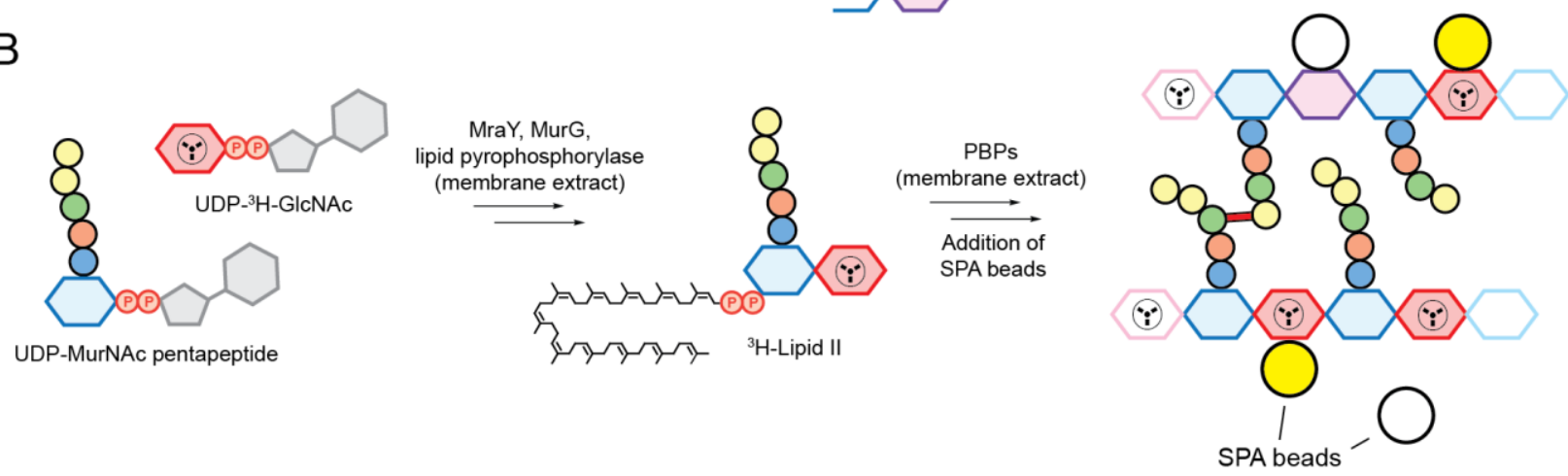

Figure 4. Approaches for monitoring peptidoglycan synthesis. (A) Degradation-based analysis of PBP activity. Purified peptidoglycan (or in vitro-synthesized enzymatic products) is digested with a muramidase, cleaving between MurNAc and GlcNAc sugars, and then treated with sodium borohydride. The peptidoglycan fragments may then be analyzed by liquid chromatography (LC), as detected by absorbance, mass spectrometry, or scintillation counting, providing an indication of the extent of transpeptidase activity [49]. (B) Incubation of uridine diphosphate (UDP)-MurNAc pentapeptide and $\left[{ }^{3} \mathrm{H}\right]$-labeled UDP-GlcNAc with an E. coli membrane extract leads to the synthesis of radiolabeled lipid II [40]. Then, PBP enzymes present in the extract catalyze peptidoglycan synthesis, incorporating the tritium label. The extent of radiolabel incorporation into peptidoglycan is measured with wheat germ agglutinin-scintillation proximity assay (SPA) beads, which bind to GlcNAc-containing polymers. The impact of inhibitors on these steps leads to lower levels of synthesized radiolabeled peptidoglycan, as can be measured in a high-throughput format. 
The need for enzymatic digestion and reduction prior to detection limits the throughput of such an approach for inhibitor discovery. Although paper chromatography has been widely applied to measure the incorporation of radiolabeled sugars and lipid intermediates into peptidoglycan without requiring degradation analyses, this technique cannot measure peptidoglycan cross-linking and thus cannot directly be used to monitor transpeptidase activity [50]. De Sousa and co-workers have developed several alternative strategies for the in vitro monitoring of peptidoglycan synthesis, based on radioactively-labeled biosynthetic precursors. Their approach uses wheat germ agglutinin-coated scintillation proximity assay (SPA) beads, which bind to GlcNAc-containing polymers (e.g., peptidoglycan). E. coli membrane extracts were incubated with $\left[{ }^{3} \mathrm{H}\right]$-labeled lipid II precursors, and the extent to which the labelled material was incorporated into peptidoglycan was determined based on the association of radioactive peptidoglycan products with the SPA beads (Figure 4B) [40]. These initial experiments simultaneously screened the activities of several enzymes present in the crude E. coli membrane extract, namely MraY, MurG, lipid pyrophosphorylase, as well as the PBPs. Perhaps unexpectedly, this assay also allowed for transpeptidase activity and inhibition to be monitored [40].

De Sousa and co-workers reported several subsequent improvements of this approach. The use of detergents allowed for E. coli PBP1b inhibitors to be distinguished from inhibitors of the other peptidoglycan biosynthetic enzymes present in the crude extract [51]. Through a related approach, radiolabelled lipid II could be prepared by incubating an E. coli strain lacking PBP1b with isotopically labeled peptidoglycan sugar precursors [52]. Following overexpression of PBP1a in this strain, the impact of inhibitors on PBP1a activity was measured by the SPA. Similarly, if exogenous PBP1b was added to the radiolabelled lipid II prepared in the membrane extracts, the 
impact of PBP1b inhibitors could be monitored. Alternatively, accumulation of radiolabelled lipid II could be triggered through the addition of vancomycin, which sequesters the lipid II peptide chain [53]. Addition of PBP substrate analogues [e.g., Ac-L-Lys(Ac)-D-Ala-D-Ala] displaced vancomycin from the radiolabeled lipid II, initiating peptidoglycan synthesis, allowing for the impact of inhibitors on this process to be measured through a high-throughput approach. These strategies have the distinct advantage of using bacterial extracts, greatly simplifying the preparation of lipid II from labelled precursors; however, due to the potential of unanticipated offtarget effects using such a complex mixture, the validation of hits through a more defined assay system is an important consideration.

These approaches have relied on the preparation of labeled lipid II through biosynthetic or chemical synthetic strategies. However, many PBPs tolerate simple substrate analogues, including those in which the carbohydrate backbone is simplified or absent, or in which the peptide chain is shortened [54,55]. In particular, the tripeptide Ac-L-Lys(Ac)-D-Ala-D-Ala has been commonly applied to monitor PBP transpeptidase and carboxypeptidase activity [56].

\section{D-Amino Acid Incorporation}

The terminal D-Ala in peptidoglycan peptide chains can be enzymatically substituted with other D-amino acids by PBPs and Ldts [46,57]. Following the formation of a covalent complex between the PBP transpeptidase domain and the donor peptide (Figure 5A), D-amino acids can act in place of the acceptor peptide, forming a peptide bond with the donor peptide [58]. The net result of this reaction is that the terminal D-Ala residue in the peptide is replaced with another D-amino acid. Lupoli et al. exploited this activity as the basis of a radioactivity assay, tracking the incorporation of $\left[{ }^{14} \mathrm{C}\right]-\mathrm{D}-\mathrm{Ala}$ into peptidoglycan by PBP1A and PBP1B from E. coli, as monitored 
with paper chromatography [59]. Such an approach did not require measurement of the extent of peptide cross-link formation, thereby offering a greatly simplified measure of transpeptidase activity.

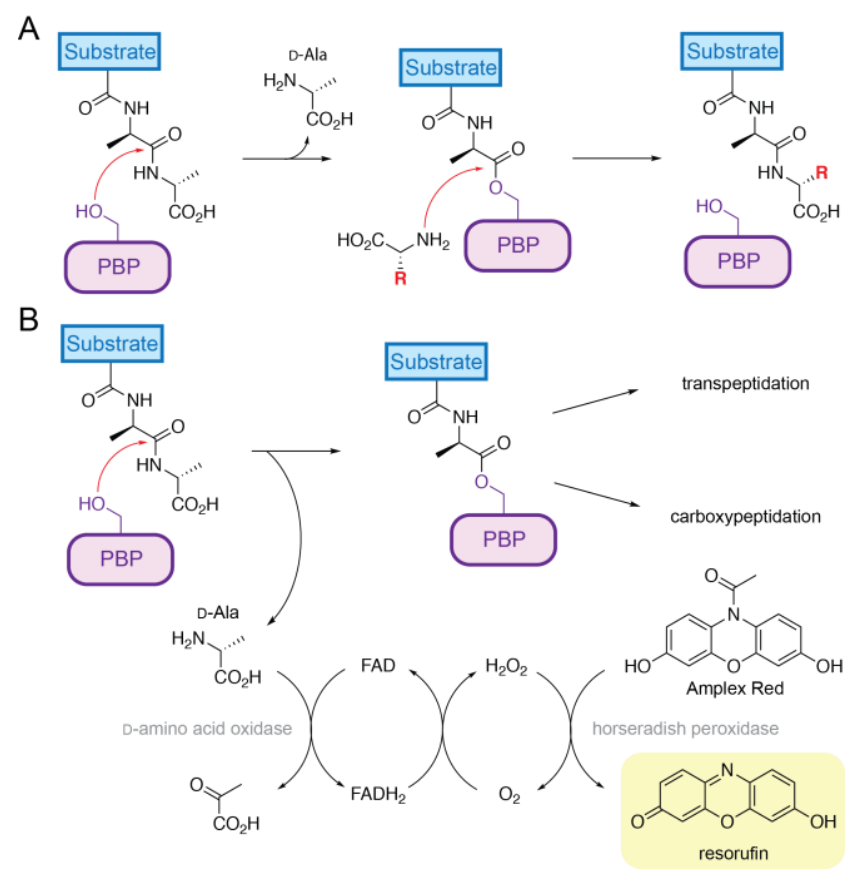

Figure 5. PBP-catalyzed D-amino acid incorporation and D-Ala release. (A) The PBP nucleophilic serine reacts with the substrate peptide, releasing D-Ala. The resultant covalent peptide-enzyme complex can then react with labeled D-amino acids (e.g., isotopically labeled, fluorescently labeled), thereby incorporating the label into the substrate $[58,60]$. (B) The release of D-Ala during PBP-catalyzed transpeptidation and carboxypeptidation reactions can be monitored through a coupled enzyme assay [61]. D-Ala is oxidized to pyruvate by D-amino acid oxidase, resulting in the formation of hydrogen peroxide. Then, the hydrogen peroxide is used by horseradish peroxidase (HRP) to oxidize Amplex Red, forming the fluorescent resorufin product. 
The PBP-mediated incorporation of D-amino acids into peptidoglycan is not limited to amino acids structurally resembling D-Ala [46,62]. Qiao et al. showed that PBP4 from Staphylococcus aureus can exchange functionalized D-Lys probes into the peptide chains present in peptidoglycan, also catalyzing this activity with monomeric lipid I and lipid II substrates (Figure 5A) [62]. This activity was used as the basis of a transpeptidase assay, measuring the incorporation of a D-Lys-biotin conjugate into peptidoglycan [62]. Following the addition of D-Lys-biotin to a culture of $S$. aureus, the cell extract was measured by Western blot through a chemiluminescence assay. Addition of a conjugate of streptavidin and horseradish peroxidase (HRP) allowed the incorporation of the biotin tag to be measured, thereby providing an indication of transpeptidase activity.

VanNieuwenhze and co-workers observed that PBPs are able to incorporate D-amino acids bearing side chain fluorophores (e.g, fluorescein, rhodamine) into peptidoglycan (Figure 5A), thereby allowing transpeptidase activity to be monitored through fluorescence measurements [63]. These fluorescent probes have provided exciting insights into peptidoglycan synthesis, allowing visualization of cell wall dynamics in live bacteria $[63,64]$. However, these procedures require washing steps to remove unincorporated amino acids for incorporation to be visualized. This was recently overcome through the use of rotor-fluorogenic D-amino acids (RfDAAs) to monitor transpeptidase activity [60]. The fluorescent signal of the RfDAAs is sensitive to their steric environment, such that their incorporation into peptidoglycan results in an increase in fluorescent intensity.

While the RfDAAs were valuable probes for monitoring peptidoglycan synthesis in live bacteria, they were also shown to be useful for monitoring PBP transpeptidase activity in vitro [60]. PBP-mediated substitution of the terminal D-Ala residue of the Ac-L-Lys(Ac)-D-Ala-D-Ala 
tripeptide with an RfDAA could be monitored in 96-well plate format through measurements of fluorescence intensity. This platform was used to show the inhibitory activity of the cephalosporin cefoxitin on the transpeptidase activity of PBP4 from S. aureus [60].

D-Ala Release (Carboxypeptidase, Transpeptidase)

The transpeptidase and carboxypeptidase activities of PBPs result in the release of Dalanine (Figure 3B, 3C, 5B), which has been used as the basis for several PBP assays. These activities can simply be monitored spectrophotometrically with simple meso-diaminopimelic acid (meso-Dap)-D-Ala-D-Ala and L-Lys-D-Ala-D-Ala tripeptide substrates [55]. However, highly sensitive fluorescence-based assays for D-Ala release have also been developed to monitor PBP activity. Gutheil et al. reported a coupled enzyme assay for measuring the release of D-Ala from a Ac-L-Lys(Ac)-D-Ala-D-Ala tripeptide by the $E$. coli carboxypeptidase PBP5 (Figure 5B) [61]. The D-Ala released from the substrate is oxidized by D-amino acid oxidase to form pyruvate and hydrogen peroxide. Then, the hydrogen peroxide is used by HRP to oxidize Amplex Red or QuantaBlu, yielding fluorescent products. These coupled assays were used to characterize the kinetic behaviour of PBP5, and monitor its inhibition by vancomycin. This highly sensitive approach is compatible with a microtiter plate format, allowing the detection of low picomole quantities of D-Ala. Several variations on this approach have since been applied by other groups $[54,56,65]$.

Adam et al. developed thioester-based probes which release a thiol upon reaction with the PBP transpeptidase nucleophilic serine, conceptually similar to the PBP-catalyzed release of DAla from peptide substrates [66]. Hydrolysis (analogous to carboxypeptidation) or transacylation (analogous to transpeptidation) of these thioesters could be monitored spectroscopically, albeit 
with the limited sensitivity associated with such measurements. However, release of the thiol could also be detected based on its reaction with 5,5'-dithiobis-(2-nitrobenzoic acid) (DTNB) or 4,4'dithiopyridine [67]. This colourimetric assay was applied to compare the kinetics of Streptomyces R61 D,D-peptidase in the crystalline and solution states.

\section{Endopeptidase Activity}

Assays for PBP endopeptidase activity often involve treatment of the bacterial peptidoglycan sacculus with purified enzyme. This may be monitored through a degradation approach similar to that shown in Figure 4A; for example, Stefanova et al. treated the PBPdegraded bacterial sacculus with cellosyl, reduced the MurNAc sugar with sodium borohydride, and analyzed the extent of endopeptidase activity by LC-MS [56]. Alternatively, endopeptidase activity could more simply be monitored through a turbidometric assay, based on enzymatic degradation of peptide cross-links in (insoluble) purified peptidoglycan $[65,68]$.

\section{$\beta$-Lactam Binding and Hydrolysis}

Several approaches for assaying PBP transpeptidase activity have focused on the specific interactions of PBPs with $\beta$-lactam antibiotics, which covalently modify the nucleophilic serine residue of the transpeptidase domain (Figure 3E). Some PBPs are capable of slowly hydrolyzing $\beta$-lactam antibiotics, and this enzymatic activity can be measured spectrophotometrically. Although chromogenic $\beta$-lactam substrates such as nitrocefin are used as the basis of a colourimetric enzyme assay [69], PBPs tend to hydrolyze $\beta$-lactams very slowly, limiting the sensitivity of a competition assay for inhibitor screening. 


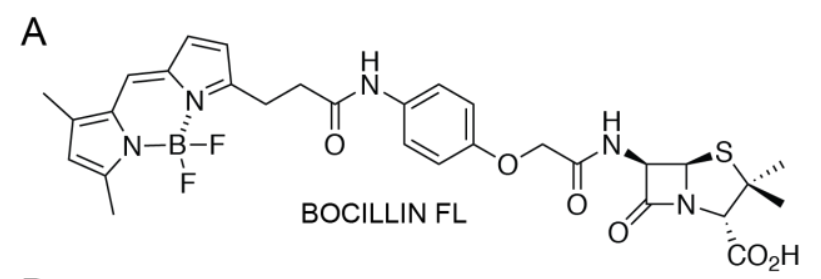

B

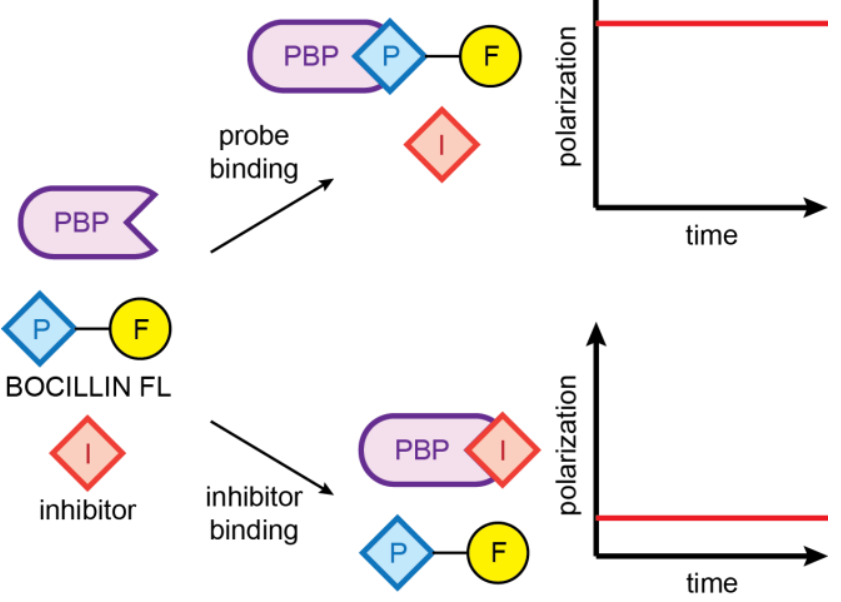

\section{Figure 6. Fluorescent approaches for monitoring inhibition of the PBP transpeptidase}

domain. (A) Chemical structure of BOCILLIN FL, a penicillin derivative bearing a borondipyrromethene (BODIPY) fluorophore. (B) Scheme showing a competition-based fluorescence polarization assay [70,71]. Binding of the fluorescent probe (here, BOCILLIN FL) to the PBP results in higher levels of fluorescence polarization. However, if an inhibitor targets the PBP active site, it blocks the fluorescent probe, decreasing the extent of fluorescence polarization.

Several fluorescently-labeled $\beta$-lactam antibiotics have been developed, including penicillins, cephalosporins, and carbapenems [72]. Many PBP inhibition studies have used BOCILLIN FL, a penicillin derivative bearing a boron-dipyrromethene (BODIPY) fluorophore on the amide side chain (Figure 6A). BOCILLIN FL is frequently used to profile the range of PBPs present in bacteria, as visualized through fluorescence-detected SDS-PAGE [73]. The competition of BOCILLIN FL with other $\beta$-lactam antibiotics for the PBP transpeptidase active site has been 
used as a means of measuring the inhibitory potency of these other antibiotics, as measured by SDS-PAGE $[73,74]$. Related approaches have been applied using radioactively labeled $\beta$-lactam antibiotics (e.g., [ $\left.{ }^{125} \mathrm{I}\right]$-labeled penicillin V) [75].

A microtiter format competition assay was developed by Stefanova et al., based on the interaction of an ampicillin-biotin conjugate with the active site of a PBP transpeptidase domain [76]. PBP1b and PBP5 from E. coli, and PBP1, PBP2, and PBP3 from Neisseria gonorrhoeae were immobilized in the wells of a microtiter plate, and treated with ampicillin-biotin conjugate alone, or in combination with an inhibitor. Following the washing out of unbound label, streptavidin conjugated to HRP was added, followed by the HRP substrates Amplex Red and hydrogen peroxide. Thus, the extent to which inhibitors compete with the ampicillin-biotin conjugate for the active site of the immobilized PBP could be fluorescently quantified, as was demonstrated with N. gonorrhoea PBP2 and ampicillin [76].

\section{Fluorescence Polarization}

In addition to SDS-PAGE-based competition assays, fluorescently-labeled $\beta$-lactam antibiotics such as BOCILLIN FL have also been used in fluorescence polarization assays to screen PBP inhibitors. These approaches are based on the interaction of fluorophores with polarized light, where the extent to which the light emitted by the fluorophore retains the initial polarization is related to the apparent size of the fluorophore. The binding of a small molecule fluorophore to a protein greatly impacts the extent of polarization of the emitted light, and so fluorescence polarization measurements can be used to determine whether a fluorescently-labeled $\beta$-lactam is bound to the PBP transpeptidase active site (Figure 6B). Thus, these measurements can show whether or not an inhibitor can prevent the labeled $\beta$-lactam from binding to the PBP. The 
application of fluorescence polarization to characterize PBPs and $\beta$-lactamases was recently reviewed [70].

Zhao et al. first developed a fluorescence polarization assay using BOCILLIN FL to compare the relative affinities of $\mathrm{PBP} 2 \mathrm{x}$ from Streptococcus pneumoniae with penicillins, cephalosporins, and carbapenems [75]. Shapiro et al. used a similar assay to measure the acylation rate constants for PBP3 from Pseudomonas aeruginosa and Acinetobacter baumannii with aztreonam, meropenem, and ceftazidime [77]. The same group later measured the acylation rates of the PBP2 from P. aeruginosa with mecillinam, faropenem, and several carbapenems [78]. In addition to the penicillin-based probes, a fluorescein-labeled derivative of the carbapenem meropenem was used in a kinetic fluorescence polarization assay with PBP3 from an Acinetobacter sp., as well as the $\beta$-lactam sensor protein BlaR1 and the serine $\beta$-lactamases AmpC and OXA-24/40 [79]. Fluorescence polarization experiments are not limited to $\beta$-lactam-type probes, as Inglis et al. employed a boronic acid tracer with a fluorescein label [80]. This boronic acid bound reversibly with modest affinity to the active sites of PBP1b from S. pneumoniae and DacA (PBP5) and DacC (PBP6) from E. coli, and its displacement from the active sites of these enzymes by $\beta$-lactam antibiotics and other boronic acids could be monitored by fluorescence polarization [80].

Fedarovich et al. reported a robust inhibitor screen for PBP2 from N. gonorrhoeae, based on a fluorescence polarization assay with BOCILLIN FL [71]. The assay was optimized for highthroughput screening, with good signal-to-noise and Z'-factor values. The authors used this assay to screen a library of 50,000 compounds against purified PBP2, yielding 32 hits which demonstrated $>50 \%$ inhibition of BOCILLIN FL binding. Of these, seven demonstrated 
antimicrobial activity against $N$. gonorrhoeae isolates, including strains which were resistant to $\beta$ lactam antibiotics.

\section{L,D-Transpeptidases}

\section{Introduction}

Some Ldts catalyze the formation of $3 \rightarrow 3$ peptide cross-links in peptidoglycan (Figure 1 ), while others catalyze the attachment of Braun's lipoprotein to peptidoglycan [7,10,81]. Although Ldts are widespread, and many bacteria encode several homologs, they tend not to be functionally essential in most bacteria [81,82]. However, the peptidoglycan of some bacteria (notably, Mycobacterium tuberculosis) contains a large proportion of $3 \rightarrow 3$ cross-links [6], and antibiotics targeting Ldts have shown promise against mycobacteria [83,84]. In other bacteria, Ldts are not essential under lab conditions, but may represent a way of overcoming inhibition of PBP transpeptidases, leading to resistance against particular $\beta$-lactam antibiotics. This was first observed with ampicillin-insensitive mutants of Enterococcus faecium, which achieved ampicillin resistance through the use of an Ldt to form cell wall cross-links [85]. In E. coli, production of the Ldt YcbB in combination with elevated synthesis of the (p)ppGpp alarmone resulted in full bypass of PBP transpeptidase activity [86]. 
A

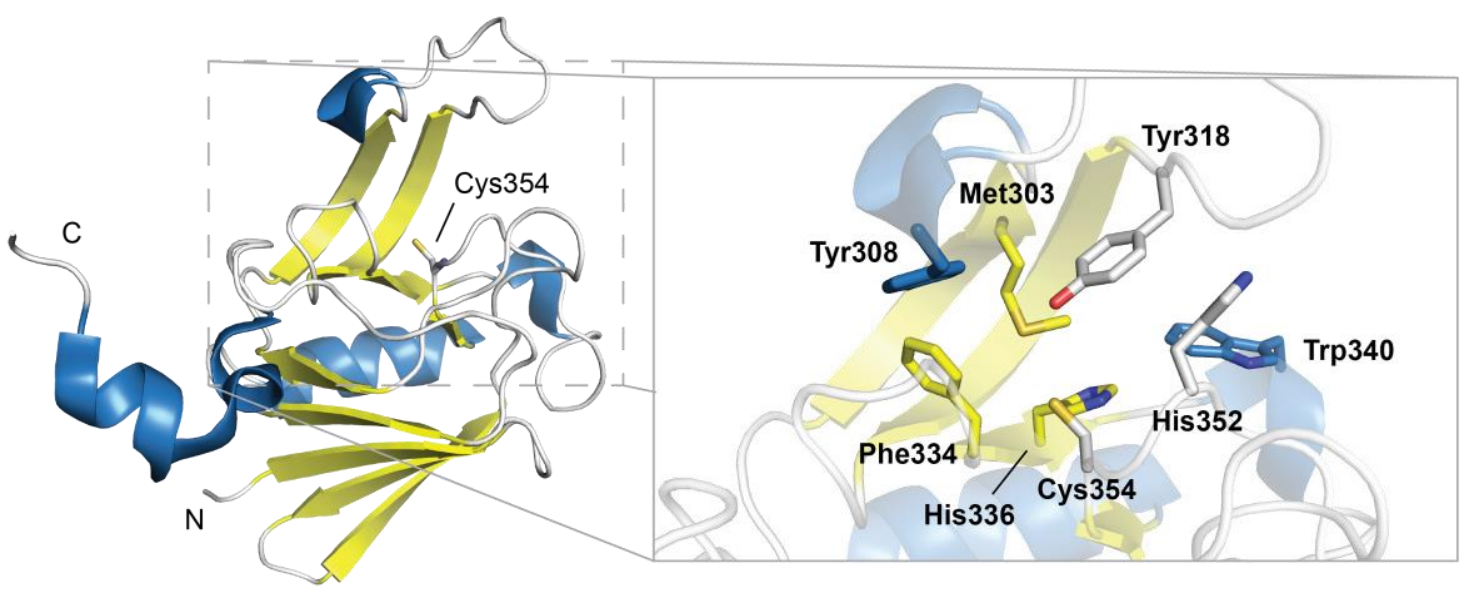

B

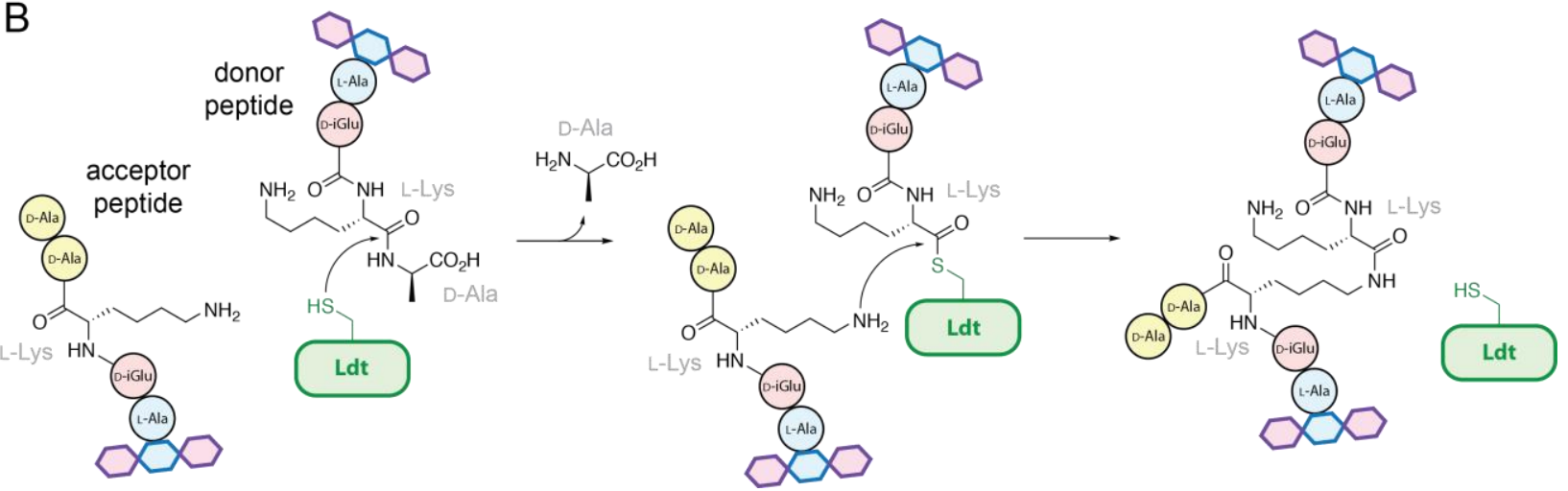

Figure 7. Overview of L,D-transpeptidase structure and mechanism. (A) View of the transpeptidase domain (residues 251 - 407) of Ldt $_{\mathrm{Mt2}}$ (PDB 6RLG) [87], with $\alpha$-helices shown in blue and $\beta$-strands in yellow. The (truncated) protein termini are indicated with $\mathrm{N}$ and $\mathrm{C}$. The inset shows the enzyme active site, representing the nucleophilic cysteine Cys354, the general base His336, and conserved hydrophobic residues as sticks. (B) Scheme showing the mechanism by which Ldts form $3 \rightarrow 3$ peptide cross-links. The structure of peptidoglycan shown corresponds to a form occurring in Gram-positive bacteria, containing L-Lys in the peptide chain. Note that the length of the glycan backbone, represented by hexagons, varies and is not fully represented in this figure. 
Due to their promise as antibiotic targets, particularly in mycobacteria, many structural studies of Ldts have recently been reported. Crystallographic and NMR studies reveal a conserved transpeptidase active site (Figure 7A) [87-89], with other more variable domains. The active site is centered around a cysteine nucleophile, with a nearby histidine residue acting as a general base [88]. This nucleophilic cysteine is present in a hydrophobic pocket, shielded by a conformationally dynamic active site "lid" [87].

While the donor peptides chains for PBP transpeptidases are pentapeptides, Ldts instead accept tetrapeptide substrates terminating in a single D-Ala residue [7]. Thus, Ldt transpeptidase activity first requires a carboxypeptidase to cleave D-Ala5 from the peptidoglycan peptide chain (Figure 1) [9]. Then, activated by a histidinyl residue [88], the active site cysteine nucleophilically attacks the peptide bond between residue 3 (generally L-Lys or meso-Dap, depending on the species) and D-Ala4, forming an covalent peptide-enzyme complex and releasing D-Ala (Figure 7B). An amino group from the acceptor peptide (typically the side chain of the third residue) nucleophilically attacks the thioester carbonyl, forming a peptide cross-link.

The most widely studied inhibitors of the Ldts are the $\beta$-lactam antibiotics, which covalently acylate the Ldt nucleophilic cysteine residue and block transpeptidase activity $[15,90]$. Although Ldts are not efficiently acylated by many penicillins and cephalosporins, the carbapenem and penem classes of $\beta$-lactam antibiotic are potent inhibitors of certain Ldts $[83,91]$. The presence of a cysteine residue in the Ldt active site provides other strategies for inhibition, including reaction with disulfides and cysteine-targeting reagents $[87,88,90]$.

\section{Assays}


Given their non-essential role in many bacteria, relatively few approaches have thus far been reported for monitoring Ldt activity and inhibition. However, inhibitor discovery for Ldts is of interest due to their key role in peptidoglycan synthesis for M. tuberculosis [84]. As may be anticipated based on their mechanistic similarities to PBPs, many of the approaches applicable to PBPs may also be used to study Ldt transpeptidase activity, although the Ldt substrate differs in terms of the peptide length. In addition, the conserved Ldt cysteine nucleophile has been exploited in the development of several alternative strategies for monitoring Ldt activity.

\section{Transpeptidase Activity}

The in vivo formation of $3 \rightarrow 3$ cell wall cross-links by Ldts has been shown through similar degradation studies to those used with PBPs (Figure 4A). Following the treatment of purified peptidoglycan with a muramidase (and, often, sodium borohydride), the muropeptides generated may be analyzed by LC-MS [85]. In vitro assays have also been performed, using MS to monitor Ldt-mediated peptide cross-link formation with disaccharide tetrapeptide substrates [8]. Like PBPs, Ldts also accept simpler substrates; Mainardi et al. showed that $\mathrm{Ldt}_{\mathrm{fm}}$ from Enterococcus faecium accepts the dipeptide Ac-L-Lys(Ac)-D-Ala as a donor, forming transpeptidation products with D-amino acids and D-2-hydroxy acids as acceptors (Figure 8A) [7].

The exchange of D-Ala4 in peptidoglycan with other amino acids occurs in vivo, as shown through the incorporation of D-Met into muropeptides by LdtA and LdtB from Vibrio cholerae (Figure 8A) [57]. This transpeptidase activity was used in an in vitro assay detecting the incorporation of $\left[{ }^{14} \mathrm{C}\right]$-D-Ala into donor peptides by $\mathrm{Ldt}_{\mathrm{fm}}$, monitoring product formation by HPLC with scintillation counting. Similar to their approach for measuring PBP transpeptidase activity (Figure 5A), Hsu et al. used D-amino acid exchange activity as the basis of an L,D-transpeptidase 
assay for LdtA from $V$. cholerae. Incorporation of a rotor-fluorogenic D-amino acid (RfDAA) into an Ac-L-Ala-D-iGlu-L-Lys(Ac)-D-Ala tetrapeptide by LdtA could be monitored based on fluorescence measurements (Figure 8A) [60].

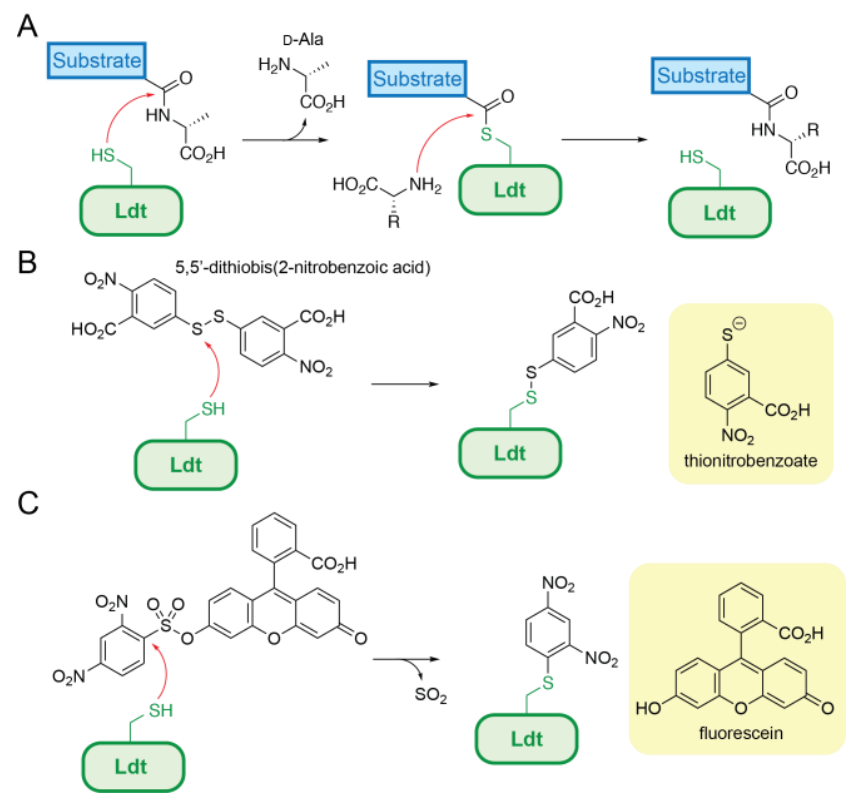

Figure 8. Strategies for monitoring L,D-transpeptidase activity and inhibition. (A) Reaction of an Ldt cysteine nucleophile with a substrate analogue, releasing D-Ala. The resulting covalent complex may then react with a labeled D-amino acid (e.g., isotopically labeled, fluorescently labeled), resulting in the incorporation of that label into the substrate $[46,60]$. (B) Reaction of the Ldt nucleophilic cysteine with 5,5'-dithiobis(2-nitrobenzoic acid) (DTNB), releasing the thionitrobenzoate chromophore [88,90]. (C) Reaction of the Ldt nucleophilic cysteine with a fluorogenic aryl sulfonate ester, releasing the fluorophore fluorescein [87,92,93].

Interactions with $\beta$-Lactams 
Although Ldts are resistant to inhibition by some classes of $\beta$-lactams, other $\beta$-lactams rapidly acylate the nucleophilic cysteine in the Ldt active site [7,15]. The acyl-enzyme complexes derived from $\beta$-lactams are often stable, although certain complexes undergo fragmentation reactions and/or slow hydrolysis [91]. The kinetics of $\beta$-lactam hydrolysis has been examined with several different Ldts, measured spectrophotometrically based on UV absorbance [94,95]. Degradation of the chromogenic $\beta$-lactam nitrocefin has also been used as part of a colourimetric assay for monitoring Ldt activity [84,96]. However, as with PBPs, the hydrolysis of $\beta$-lactams by Ldts tends to be prohibitively slow for assay development.

\section{Thiol-Selective Probes}

The cysteine nucleophile in the Ldt active site has been shown to form disulfides with thiols [96], and to undergo exchange with disulfides $[88,90]$. This latter activity was used as the basis of colourimetric assay for $\mathrm{Ldt}_{\mathrm{Mt} 2}$ from $M$. tuberculosis, using 5,5'-dithiobis-(2-nitrobenzoic acid) (DTNB; Ellman's reagent) (Figure 8B) [90]. Reaction of DTNB with the Ldt cysteine results in the release of the thionitrobenzoate chromophore. The impact of inhibitors on the ability of the active site cysteine to react with DTNB was then used as the basis of a colourimetric competition assay, as demonstrated with a panel of $\beta$-lactam antibiotics [90].

Inspired by the DTNB strategy, thiol-selective fluorogenic probes were used to develop a fluorescence-based $\mathrm{Ldt}_{\mathrm{Mt} 2}$ inhibition assay. Dinitrophenyl derivatives of fluorescein and benzoxadiazole fluorophores were shown to react with the Ldt $\mathrm{Mt}_{2}$ nucleophilic cysteine, arylating the cysteine residue, and releasing the fluorophore (Figure 8C) [92]. This assay was shown to be highly sensitive, using nanomolar concentrations of enzyme, and is amenable to high-throughput screening approaches. Using a competition strategy, these fluorogenic probes were applied to 
screen a library of $\beta$-lactam antibiotics as $\mathrm{Ldt}_{\mathrm{Mt} 2}$ inhibitors, revealing potent inhibition by the carbapenem and penem antibiotic sub-classes [92]. A subsequent study using this assay showed that common cysteine-targeting reagents, such as ebselen, may represent promising scaffolds for developing potent $\mathrm{Ldt}_{\mathrm{Mt} 2}$ inhibitors [87].

\section{Conclusions and Future Outlook}

Bacterial transpeptidases are established antibiotic targets, but the continuing emergence of multidrug resistant bacteria necessitates the discovery of new inhibitors for these enzymes. In this review, we have highlighted the diverse range of assays available for monitoring the activity and inhibition of PBP transpeptidases and Ldts. Although several factors complicate inhibitor discovery for PBPs and Ldts, particularly the complexity of their substrates, recent mechanistic insights have provided promising strategies for assay development. Many of these approaches have been validated with known antibiotics, but it is often unclear to what extent they have been applied to identify new transpeptidase inhibitors.

Strategies used to screen other antibiotic targets are also worth applying to transpeptidases; for example, Wolan and co-workers recently developed an in vitro Förster resonance energy transfer (FRET)-based assay for the E. coli lipoprotein signal peptidase (Lsp), allowing the authors to screen $>600,000$ compounds, ultimately leading to antibiotic candidates with nanomolar level $\mathrm{IC}_{50}$ values [97]. As a complementary approach to in vivo and in vitro assays, computational screens of transpeptidase inhibitors have also shown promise [98-100]. Nonetheless, the arsenal of currently available PBP and Ldt assays represent a valuable resource for the discovery of new antibiotics, as many of these assays are amenable to the efficient high-throughput screening of libraries of natural products and synthetic compounds. 


\section{Acknowledgements}

We are grateful to Queen's University in Kingston, Canada (C.T.L.) and Queen's University Belfast (S.A.C.) for financial support.

\section{Funding Sources}

Funding: This work was supported by the Engineering and Physical Sciences Research Council (S.A.C.) [grant numbers EP/S015892/1].

\section{References}

[1] Silhavy, T. J., Kahne, D., and Walker, S. The bacterial cell envelope, Cold Spring Harbor Perspect Biol 2 (2010) a000414.

[2] Vollmer, W., Blanot, D., and De Pedro, M. A. Peptidoglycan structure and architecture, FEMS Microbiol Rev 32 (2008) 149-167.

[3] Breukink, E., and de Kruijff, B. Lipid II as a target for antibiotics, Nature reviews Drug discovery 5 (2006) 321.

[4] Sauvage, E., Kerff, F., Terrak, M., Ayala, J. A., and Charlier, P. The penicillin-binding proteins: structure and role in peptidoglycan biosynthesis, FEMS Microbiol Rev 32 (2008) 234-258.

[5] Taguchi, A., Welsh, M. A., Marmont, L. S., Lee, W., Sjodt, M., Kruse, A. C., Kahne, D., Bernhardt, T. G., and Walker, S. FtsW is a peptidoglycan polymerase that is functional only in complex with its cognate penicillin-binding protein, Nat Microbiol 4 (2019) 587. 
[6] Lavollay, M., Arthur, M., Fourgeaud, M., Dubost, L., Marie, A., Veziris, N., Blanot, D., Gutmann, L., and Mainardi, J.-L. The peptidoglycan of stationary-phase Mycobacterium tuberculosis predominantly contains cross-links generated by L, D-transpeptidation, J Bacteriol 190 (2008) 4360-4366.

[7] Mainardi, J.-L., Fourgeaud, M., Hugonnet, J.-E., Dubost, L., Brouard, J.-P., Ouazzani, J., Rice, L. B., Gutmann, L., and Arthur, M. A novel peptidoglycan cross-linking enzyme for a $\beta$-lactamresistant transpeptidation pathway, J Biol Chem 280 (2005) 38146-38152.

[8] Gupta, R., Lavollay, M., Mainardi, J.-L., Arthur, M., Bishai, W. R., and Lamichhane, G. The Mycobacterium tuberculosis protein Ldt $\mathrm{Mt} 2$ is a nonclassical transpeptidase required for virulence and resistance to amoxicillin, Nat Med 16 (2010) 466.

[9] Sacco, E., Hugonnet, J. E., Josseaume, N., Cremniter, J., Dubost, L., Marie, A., Patin, D., Blanot, D., Rice, L. B., and Mainardi, J. L. Activation of the 1, d-transpeptidation peptidoglycan cross-linking pathway by a metallo-d, d-carboxypeptidase in Enterococcus faecium, Mol Microbiol 75 (2010) 874-885.

[10] Magnet, S., Bellais, S., Dubost, L., Fourgeaud, M., Mainardi, J.-L., Petit-Frère, S., Marie, A., Mengin-Lecreulx, D., Arthur, M., and Gutmann, L. Identification of the L, D-transpeptidases responsible for attachment of the Braun lipoprotein to Escherichia coli peptidoglycan, J Bacteriol 189 (2007) 3927-3931.

[11] Mazmanian, S. K., Liu, G., Ton-That, H., and Schneewind, O. Staphylococcus aureus sortase, an enzyme that anchors surface proteins to the cell wall, Science 285 (1999) 760-763.

[12] Wang, Q. M., Peery, R. B., Johnson, R. B., Alborn, W. E., Yeh, W.-K., and Skatrud, P. L. Identification and characterization of a monofunctional glycosyltransferase from Staphylococcus aureus, J Bacteriol 183 (2001) 4779-4785. 
[13] Silver, L. L. Does the cell wall of bacteria remain a viable source of targets for novel antibiotics?, Biochem Pharmacol 71 (2006) 996-1005.

[14] Bush, K., and Macielag, M. J. New $\beta$-lactam antibiotics and $\beta$-lactamase inhibitors, Expert Opin Ther Pat 20 (2010) 1277-1293.

[15] Mainardi, J.-L., Hugonnet, J.-E., Rusconi, F., Fourgeaud, M., Dubost, L., Moumi, A. N., Delfosse, V., Mayer, C., Gutmann, L., and Rice, L. B. Unexpected inhibition of peptidoglycan ldtranspeptidase from Enterococcus faecium by the $\beta$-lactam imipenem, J Biol Chem 282 (2007) 30414-30422.

[16] Bush, K., and Jacoby, G. A. Updated functional classification of $\beta$-lactamases, Antimicrob Agents Chemother 54 (2010) 969-976.

[17] Blair, J. M., Webber, M. A., Baylay, A. J., Ogbolu, D. O., and Piddock, L. J. Molecular mechanisms of antibiotic resistance, Nat Rev Microbiol 13 (2015) 42.

[18] Papp-Wallace, K. M., Endimiani, A., Taracila, M. A., and Bonomo, R. A. Carbapenems: past, present, and future, Antimicrob Agents Chemother 55 (2011) 4943-4960.

[19] Chen, X., Wong, C. H., and Ma, C. Targeting the Bacterial Transglycosylase: Antibiotic Development from a Structural Perspective, ACS Infect Dis 5 (2019) 1493-1504.

[20] Blanchaert, B., Adams, E., and Van Schepdael, A. An overview of analytical methods for monitoring bacterial transglycosylation, Anal Methods 6 (2014) 7590-7596.

[21] Cascioferro, S., Raffa, D., Maggio, B., Raimondi, M. V., Schillaci, D., and Daidone, G. Sortase A inhibitors: recent advances and future perspectives, J Med Chem 58 (2015) 9108-9123. [22] Egan, A. J., Biboy, J., van't Veer, I., Breukink, E., and Vollmer, W. Activities and regulation of peptidoglycan synthases, Philos Trans R Soc Lond B Biol Sci 370 (2015). 
[23] Taguchi, A., Kahne, D., and Walker, S. Chemical tools to characterize peptidoglycan synthases, Curr Opin Chem Biol 53 (2019) 44-50.

[24] Typas, A., Banzhaf, M., Gross, C. A., and Vollmer, W. From the regulation of peptidoglycan synthesis to bacterial growth and morphology, Nat Rev Microbiol 10 (2012) 123.

[25] Münch, D., and Sahl, H.-G. Structural variations of the cell wall precursor lipid II in Grampositive bacteria-Impact on binding and efficacy of antimicrobial peptides, BBA - Biomembranes 1848 (2015) 3062-3071.

[26] Schwartz, B., Markwalder, J. A., and Wang, Y. Lipid II: Total synthesis of the bacterial cell wall precursor and utilization as a substrate for glycosyltransfer and transpeptidation by penicillin binding protein (PBP) 1b of Eschericia coli, J Am Chem Soc 123 (2001) 11638-11643.

[27] VanNieuwenhze, M. S., Mauldin, S. C., Zia-Ebrahimi, M., Winger, B. E., Hornback, W. J., Saha, S. L., Aikins, J. A., and Blaszczak, L. C. The first total synthesis of lipid II: the final monomeric intermediate in bacterial cell wall biosynthesis, J Am Chem Soc 124 (2002) 3656-3660. [28] Bann, S. J., Ballantine, R. D., McCallion, C. E., Qian, P.-Y., Li, Y.-X., and Cochrane, S. A. A Chemical-Intervention Strategy To Circumvent Peptide Hydrolysis by d-Stereoselective Peptidases, J Med Chem 62 (2019) 10466-10472.

[29] Dong, Y. Y., Wang, H., Pike, A. C., Cochrane, S. A., Hamedzadeh, S., Wyszyński, F. J., Bushell, S. R., Royer, S. F., Widdick, D. A., and Sajid, A. Structures of DPAGT1 explain glycosylation disease mechanisms and advance TB antibiotic design, Cell 175 (2018) 1045-1058. e1016.

[30] Cochrane, S. A., Findlay, B., Bakhtiary, A., Acedo, J. Z., Rodriguez-Lopez, E. M., Mercier, P., and Vederas, J. C. Antimicrobial lipopeptide tridecaptin A1 selectively binds to Gram-negative lipid II, Proc Natl Acad Sci USA 113 (2016) 11561-11566. 
[31] Huang, S. H., Wu, W. S., Huang, L. Y., Huang, W. F., Fu, W. C., Chen, P. T., Fang, J. M., Cheng, W. C., Cheng, T. J. R., and Wong, C. H. New Continuous Fluorometric Assay for Bacterial Transglycosylase Using Forster Resonance Energy Transfer, J Am Chem Soc 135 (2013) 1707817089.

[32] Dumbre, S., Derouaux, A., Lescrinier, E., Piette, A., Joris, B., Terrak, M., and Herdewijn, P. Synthesis of modified peptidoglycan precursor analogues for the inhibition of glycosyltransferase, J Am Chem Soc 134 (2012) 9343-9351.

[33] Liu, C.-Y., Guo, C.-W., Chang, Y.-F., Wang, J.-T., Shih, H.-W., Hsu, Y.-F., Chen, C.-W., Chen, S.-K., Wang, Y.-C., and Cheng, T.-J. R. Synthesis and evaluation of a new fluorescent transglycosylase substrate: Lipid II-based molecule possessing a dansyl-C20 polyprenyl moiety, Org Lett 12 (2010) 1608-1611.

[34] Breukink, E., van Heusden, H. E., Vollmerhaus, P. J., Swiezewska, E., Brunner, L., Walker, S., Heck, A. J., and de Kruijff, B. Lipid II is an intrinsic component of the pore induced by nisin in bacterial membranes, J Biol Chem 278 (2003) 19898-19903.

[35] Mitachi, K., Yun, H. G., Gillman, C. D., Skorupinska-Tudek, K., Swiezewska, E., Clemons Jr, W. M., and Kurosu, M. Substrate Tolerance of Bacterial Glycosyltransferase MurG: Novel Fluorescence-based Assays, ACS Infect Dis (2019).

[36] Chen, K.-T., Chen, P.-T., Lin, C.-K., Huang, L.-Y., Hu, C.-M., Chang, Y.-F., Hsu, H.-T., Cheng, T.-J. R., Wu, Y.-T., and Cheng, W.-C. Structural investigation of Park's nucleotide on bacterial translocase MraY: Discovery of unexpected MraY inhibitors, Sci Rep 6 (2016) 31579. [37] Lebar, M. D., Lupoli, T. J., Tsukamoto, H., May, J. M., Walker, S., and Kahne, D. Forming cross-linked peptidoglycan from synthetic gram-negative Lipid II, J Am Chem Soc 135 (2013) $4632-4635$. 
[38] Qiao, Y., Srisuknimit, V., Rubino, F., Schaefer, K., Ruiz, N., Walker, S., and Kahne, D. Lipid II overproduction allows direct assay of transpeptidase inhibition by beta-lactams, Nat Chem Biol 13 (2017) 793-798.

[39] Liang, H., DeMeester, K. E., Hou, C.-W., Parent, M. A., Caplan, J. L., and Grimes, C. L. Metabolic labelling of the carbohydrate core in bacterial peptidoglycan and its applications, Nat Commun 8 (2017) 15015.

[40] Chandrakala, B., Elias, B. C., Mehra, U., Umapathy, N., Dwarakanath, P., Balganesh, T., and deSousa, S. M. Novel Scintillation Proximity Assay for Measuring Membrane-Associated Steps of Peptidoglycan Biosynthesis in Escherichia coli, Antimicrob Agents Chemother 45 (2001) 768775.

[41] McDonough, M. A., Anderson, J. W., Silvaggi, N. R., Pratt, R., Knox, J. R., and Kelly, J. A. Structures of two kinetic intermediates reveal species specificity of penicillin-binding proteins, $J$ Mol Biol 322 (2002) 111-122.

[42] Lim, D., and Strynadka, N. C. Structural basis for the $\beta$ lactam resistance of PBP2a from methicillin-resistant Staphylococcus aureus, Nat Struct Mol Biol 9 (2002) 870.

[43] Sung, M.-T., Lai, Y.-T., Huang, C.-Y., Chou, L.-Y., Shih, H.-W., Cheng, W.-C., Wong, C.H., and Ma, C. Crystal structure of the membrane-bound bifunctional transglycosylase PBP1b from Escherichia coli, Proc Natl Acad Sci USA 106 (2009) 8824-8829.

[44] Chen, Y., Zhang, W., Shi, Q., Hesek, D., Lee, M., Mobashery, S., and Shoichet, B. K. Crystal structures of penicillin-binding protein 6 from Escherichia coli, J Am Chem Soc 131 (2009) 1434514354. 
[45] Fedarovich, A., Nicholas, R. A., and Davies, C. Unusual conformation of the SxN motif in the crystal structure of penicillin-binding protein A from Mycobacterium tuberculosis, J Mol Biol 398 (2010) 54-65.

[46] Horcajo, P., de Pedro, M. A., and Cava, F. Peptidoglycan plasticity in bacteria: stress-induced peptidoglycan editing by noncanonical D-amino acids, Microb Drug Resist 18 (2012) 306-313.

[47] Vollmer, W., and Bertsche, U. Murein (peptidoglycan) structure, architecture and biosynthesis in Escherichia coli, Biochimica et Biophysica Acta (BBA)-Biomembranes 1778 (2008) 1714-1734.

[48] Glauner, B. Separation and quantification of muropeptides with high-performance liquid chromatography, Anal Biochem 172 (1988) 451-464.

[49] Biboy, J., Bui, N. K., and Vollmer, W. In vitro peptidoglycan synthesis assay with lipid II substrate, Methods Mol Biol 966 (2013) 273-288.

[50] Izaki, K., Matsuhashi, M., and Strominger, J. L. Biosynthesis of the Peptidoglycan of Bacterial Cell Walls XIII. Peptidoglycan Transpeptidase and D-Alanine Carboxypeptidase: Penicillin-Sensitive Enzymatic Reaction in Strains of Escherichia coli, J Biol Chem 243 (1968) 3180-3192.

[51] Chandrakala, B., Shandil, R. K., Mehra, U., Ravishankar, S., Kaur, P., Usha, V., Joe, B., and deSousa, S. M. High-throughput screen for inhibitors of transglycosylase and/or transpeptidase activities of Escherichia coli penicillin binding protein 1b, Antimicrob Agents Chemother 48 (2004) 30-40.

[52] Ramachandran, V., Chandrakala, B., Kumar, V. P., Usha, V., Solapure, S. M., and de Sousa, S. M. Screen for inhibitors of the coupled transglycosylase-transpeptidase of peptidoglycan biosynthesis in Escherichia coli, Antimicrob Agents Chemother 50 (2006) 1425-1432. 
[53] Kumar, V. P., Basavannacharya, C., and de Sousa, S. M. A microplate assay for the coupled transglycosylase-transpeptidase activity of the penicillin binding proteins; a vancomycinneutralizing tripeptide combination prevents penicillin inhibition of peptidoglycan synthesis, Biochem Biophys Res Commun 450 (2014) 347-352.

[54] Hesek, D., Suvorov, M., Morio, K.-i., Lee, M., Brown, S., Vakulenko, S. B., and Mobashery, S. Synthetic peptidoglycan substrates for penicillin-binding protein 5 of Gram-negative bacteria, J Org Chem 69 (2004) 778-784.

[55] Anderson, J. W., Adediran, S. A., Charlier, P., Nguyen-Distèche, M., Frère, J.-M., Nicholas, R. A., and Pratt, R. F. On the substrate specificity of bacterial DD-peptidases: evidence from two series of peptidoglycan-mimetic peptides, Biochem J 373 (2003) 949-955.

[56] Stefanova, M. E., Tomberg, J., Olesky, M., Höltje, J.-V., Gutheil, W. G., and Nicholas, R. A. Neisseria gonorrhoeae penicillin-binding protein 3 exhibits exceptionally high carboxypeptidase and $\beta$-lactam binding activities, Biochemistry 42 (2003) 14614-14625.

[57] Cava, F., De Pedro, M. A., Lam, H., Davis, B. M., and Waldor, M. K. Distinct pathways for modification of the bacterial cell wall by non-canonical D-amino acids, EMBO J 30 (2011) 34423453.

[58] Lupoli, T. J., Tsukamoto, H., Doud, E. H., Wang, T.-S. A., Walker, S., and Kahne, D. Transpeptidase-mediated incorporation of D-amino acids into bacterial peptidoglycan, J Am Chem Soc 133 (2011) 10748-10751.

[59] Lupoli, T. J., Lebar, M. D., Markovski, M., Bernhardt, T., Kahne, D., and Walker, S. Lipoprotein activators stimulate Escherichia coli penicillin-binding proteins by different mechanisms, J Am Chem Soc 136 (2013) 52-55. 
[60] Hsu, Y. P., Hall, E., Booher, G., Murphy, B., Radkov, A. D., Yablonowski, J., Mulcahey, C., Alvarez, L., Cava, F., Brun, Y. V., Kuru, E., and VanNieuwenhze, M. S. Fluorogenic D-amino acids enable real-time monitoring of peptidoglycan biosynthesis and high-throughput transpeptidation assays, Nat Chem 11 (2019) 335-341.

[61] Gutheil, W. G., Stefanova, M. E., and Nicholas, R. A. Fluorescent coupled enzyme assays for D-alanine: application to penicillin-binding protein and vancomycin activity assays, Anal Biochem 287 (2000) 196-202.

[62] Qiao, Y., Lebar, M. D., Schirner, K., Schaefer, K., Tsukamoto, H., Kahne, D., and Walker, S. Detection of lipid-linked peptidoglycan precursors by exploiting an unexpected transpeptidase reaction, J Am Chem Soc 136 (2014) 14678-14681.

[63] Kuru, E., Hughes, H. V., Brown, P. J., Hall, E., Tekkam, S., Cava, F., de Pedro, M. A., Brun, Y. V., and VanNieuwenhze, M. S. In situ probing of newly synthesized peptidoglycan in live bacteria with fluorescent D-amino acids, Angew Chem Int Ed Engl 51 (2012) 12519-12523.

[64] Kuru, E., Tekkam, S., Hall, E., Brun, Y. V., and Van Nieuwenhze, M. S. Synthesis of fluorescent D-amino acids and their use for probing peptidoglycan synthesis and bacterial growth in situ, Nat Protoc 10 (2015) 33.

[65] Clarke, T. B., Kawai, F., Park, S. Y., Tame, J. R., Dowson, C. G., and Roper, D. I. Mutational analysis of the substrate specificity of Escherichia coli penicillin binding protein 4, Biochemistry 48 (2009) 2675-2683.

[66] Adam, M., Damblon, C., Jamin, M., Zorzi, W., Dusart, V., Galleni, M., El Kharroubi, A., Piras, G., Spratt, B. G., and Keck, W. Acyltransferase activities of the high-molecular-mass essential penicillin-binding proteins, Biochem J 279 (1991) 601-604. 
[67] Kelly, J. A., Waley, S. G., Adam, M., and Frère, J.-M. Crystalline enzyme kinetics: activity of the Streptomyces R61 D-alanyl-D-alanine peptidase, Biochimica et Biophysica Acta (BBA)Protein Structure and Molecular Enzymology 1119 (1992) 256-260.

[68] Hash, J. H. Measurement of bacteriolytic enzymes, J Bacteriol 93 (1967) 1201.

[69] Graves-Woodward, K., and Pratt, R. Reaction of soluble penicillin-binding protein 2a of methicillin-resistant Staphylococcus aureus with $\beta$-lactams and acyclic substrates: kinetics in homogeneous solution, Biochem J 332 (1998) 755-761.

[70] Shapiro, A. B. Investigation of beta-lactam antibacterial drugs, beta-lactamases, and penicillin-binding proteins with fluorescence polarization and anisotropy: a review, Methods Appl Fluoresc 4 (2016) 024002.

[71] Fedarovich, A., Djordjevic, K. A., Swanson, S. M., Peterson, Y. K., Nicholas, R. A., and Davies, C. High-throughput screening for novel inhibitors of Neisseria gonorrhoeae penicillinbinding protein 2, PLoS One 7 (2012) e44918.

[72] Stone, M. R. L., Butler, M. S., Phetsang, W., Cooper, M. A., and Blaskovich, M. A. T. Fluorescent Antibiotics: New Research Tools to Fight Antibiotic Resistance, Trends Biotechnol 36 (2018) 523-536.

[73] Moyá, B., Beceiro, A., Cabot, G., Juan, C., Zamorano, L., Alberti, S., and Oliver, A. Pan- $\beta$ lactam resistance development in Pseudomonas aeruginosa clinical strains: molecular mechanisms, penicillin-binding protein profiles, and binding affinities, Antimicrob Agents Chemother 56 (2012) 4771-4778.

[74] King, D. T., Wasney, G. A., Nosella, M., Fong, A., and Strynadka, N. C. Structural insights into inhibition of Escherichia coli penicillin-binding protein 1B, J Biol Chem 292 (2017) 979-993. 
[75] Zhao, G., Meier, T. I., Kahl, S. D., Gee, K. R., and Blaszczak, L. C. BOCILLIN FL, a sensitive and commercially available reagent for detection of penicillin-binding proteins, Antimicrob Agents Chemother 43 (1999) 1124-1128.

[76] Stefanova, M., Bobba, S., and Gutheil, W. G. A microtiter plate-based beta-lactam binding assay for inhibitors of high-molecular-mass penicillin-binding proteins, Anal Biochem 396 (2010) 164-166.

[77] Shapiro, A. B., Gu, R.-F., Gao, N., Livchak, S., and Thresher, J. Continuous fluorescence anisotropy-based assay of BOCILLIN FL penicillin reaction with penicillin binding protein 3, Anal Biochem 439 (2013) 37-43.

[78] Shapiro, A. B., Gao, N., Gu, R.-F., and Thresher, J. Fluorescence anisotropy-based measurement of Pseudomonas aeruginosa penicillin-binding protein 2 transpeptidase inhibitor acylation rate constants, Anal Biochem 463 (2014) 15-22.

[79] June, C. M., Vaughan, R. M., Ulberg, L. S., Bonomo, R. A., Witucki, L. A., and Leonard, D. A. A fluorescent carbapenem for structure function studies of penicillin-binding proteins, $\beta$ lactamases, and $\beta$-lactam sensors, Anal Biochem 463 (2014) 70-74.

[80] Inglis, S. R., Strieker, M., Rydzik, A. M., Dessen, A., and Schofield, C. J. A boronic-acidbased probe for fluorescence polarization assays with penicillin binding proteins and betalactamases, Anal Biochem 420 (2012) 41-47.

[81] Magnet, S., Dubost, L., Marie, A., Arthur, M., and Gutmann, L. Identification of the L, Dtranspeptidases for peptidoglycan cross-linking in Escherichia coli, J Bacteriol 190 (2008) 47824785. 
[82] Zandi, T., Marshburn, R. L., Stateler, P. K., and Brammer Basta, L. Phylogenetic and biochemical analyses of mycobacterial L, D-transpeptidases reveal a distinct enzyme class that is preferentially acylated by meropenem, ACS Infect Dis (2019).

[83] Dhar, N., Dubée, V., Ballell, L., Cuinet, G., Hugonnet, J.-E., Signorino-Gelo, F., Barros, D., Arthur, M., and McKinney, J. D. Rapid cytolysis of Mycobacterium tuberculosis by faropenem, an orally bioavailable $\beta$-lactam antibiotic, Antimicrob Agents Chemother 59 (2015) 1308-1319.

[84] Kumar, P., Kaushik, A., Lloyd, E. P., Li, S.-G., Mattoo, R., Ammerman, N. C., Bell, D. T., Perryman, A. L., Zandi, T. A., and Ekins, S. Non-classical transpeptidases yield insight into new antibacterials, Nat Chem Biol 13 (2017) 54.

[85] Mainardi, J.-L., Legrand, R., Arthur, M., Schoot, B., van Heijenoort, J., and Gutmann, L. Novel mechanism of $\beta$-lactam resistance due to bypass of DD-transpeptidation in Enterococcus faecium, J Biol Chem 275 (2000) 16490-16496.

[86] Hugonnet, J.-E., Mengin-Lecreulx, D., Monton, A., Den Blaauwen, T., Carbonnelle, E., Veckerle, C., Yves, V. B., Van Nieuwenhze, M., Bouchier, C., and Tu, K. Factors essential for L, D-transpeptidase-mediated peptidoglycan cross-linking and $\beta$-lactam resistance in Escherichia coli, Elife 5 (2016) e19469.

[87] de Munnik, M., Lohans, C. T., Lang, P. A., Langley, G. W., Malla, T. R., Tumber, A., Schofield, C. J., and Brem, J. Targeting the Mycobacterium tuberculosis transpeptidase LdtMt2 with cysteine-reactive inhibitors including ebselen, Chem Commun (Camb) 55 (2019) 1021410217.

[88] Lecoq, L., Bougault, C., Hugonnet, J.-E., Veckerlé, C., Pessey, O., Arthur, M., and Simorre, J.-P. Dynamics Induced by $\beta$-Lactam Antibiotics in the Active Site of Bacillus subtilisl, dTranspeptidase, Structure 20 (2012) 850-861. 
[89] Lecoq, L., Dubée, V., Triboulet, S. b., Bougault, C., Hugonnet, J.-E., Arthur, M., and Simorre, J.-P. Structure of Enterococcus faecium L, D-transpeptidase acylated by ertapenem provides insight into the inactivation mechanism, ACS Chem Biol 8 (2013) 1140-1146.

[90] Steiner, E. M., Schneider, G., and Schnell, R. Binding and processing of $\beta$-lactam antibiotics by the transpeptidase LdtMt2 from Mycobacterium tuberculosis, FEBS J 284 (2017) 725-741.

[91] Lohans, C. T., Chan, H. H., Malla, T. R., Kumar, K., Kamps, J. J., McArdle, D. J., van Groesen, E., de Munnik, M., Tooke, C. L., and Spencer, J. Non-Hydrolytic $\beta$-Lactam Antibiotic Fragmentation by 1, d-Transpeptidases and Serine $\beta$-Lactamase Cysteine Variants, Angew Chem Int Ed Engl 58 (2019) 1990-1994.

[92] de Munnik, M., Lohans, C. T., Langley, G. W., Bon, C., Brem, J., and Schofield, C. J. A Fluorescence-Based Assay for Screening beta-Lactams Targeting the Mycobacterium tuberculosis Transpeptidase LdtMt2, ChemBioChem 21 (2020) 368-372.

[93] Maeda, H., Matsuno, H., Ushida, M., Katayama, K., Saeki, K., and Itoh, N. 2, 4Dinitrobenzenesulfonyl fluoresceins as fluorescent alternatives to Ellman's reagent in thiolquantification enzyme assays, Angew Chem Int Ed Engl 44 (2005) 2922-2925.

[94] Dubée, V., Triboulet, S., Mainardi, J.-L., Ethève-Quelquejeu, M., Gutmann, L., Marie, A., Dubost, L., Hugonnet, J.-E., and Arthur, M. Inactivation of Mycobacterium tuberculosis L, Dtranspeptidase LdtMt1 by carbapenems and cephalosporins, Antimicrob Agents Chemother 56 (2012) 4189-4195.

[95] Triboulet, S., Dubée, V., Lecoq, L., Bougault, C., Mainardi, J.-L., Rice, L. B., EthèveQuelquejeu, M., Gutmann, L., Marie, A., and Dubost, L. Kinetic features of L, D-transpeptidase inactivation critical for $\beta$-lactam antibacterial activity, PLoS One 8 (2013) e67831. 
[96] Erdemli, S. B., Gupta, R., Bishai, W. R., Lamichhane, G., Amzel, L. M., and Bianchet, M. A. Targeting the cell wall of Mycobacterium tuberculosis: structure and mechanism of L, Dtranspeptidase 2, Structure 20 (2012) 2103-2115.

[97] Kitamura, S., Owensby, A., Wall, D., and Wolan, D. W. Lipoprotein signal peptidase inhibitors with antibiotic properties identified through design of a robust in vitro HT platform, Cell Chem Biol 25 (2018) 301-308. e312.

[98] Billones, J. B., Carrillo, M. C., Organo, V. G., Macalino, S. J., Sy, J. B., Emnacen, I. A., Clavio, N. A., and Concepcion, G. P. Toward antituberculosis drugs: in silico screening of synthetic compounds against Mycobacterium tuberculosis 1,d-transpeptidase 2, Drug Des Devel Ther 10 (2016) 1147-1157.

[99] Sabe, V. T., Tolufashe, G. F., Ibeji, C. U., Maseko, S. B., Govender, T., Maguire, G. E., Lamichhane, G., Honarparvar, B., and Kruger, H. G. Identification of potent L, D-transpeptidase 5 inhibitors for Mycobacterium tuberculosis as potential anti-TB leads: virtual screening and molecular dynamics simulations, J Mol Model 25 (2019) 328.

[100] Miguet, L., Zervosen, A., Gerards, T., Pasha, F. A., Luxen, A., Disteche-Nguyen, M., and Thomas, A. Discovery of new inhibitors of resistant Streptococcus pneumoniae penicillin binding protein (PBP) 2x by structure-based virtual screening, J Med Chem 52 (2009) 5926-5936. 